\title{
Precios y crisis en una economía rioplatense. Santa Fe (1790-1850)
}

\author{
Prices and Crisis in Rio de la Plata. \\ Santa Fe (1790-1850)
}

\author{
Carina Frid* \\ Universidad Nacional de Rosario, Santa Fe, Argentina, email: carinafrid@gmail.com
}

\begin{abstract}
Resumen: El estudio examina la evolución de los precios en el distrito rioplatense de Santa Fe desde finales de la colonia (cuando los precios de bienes transables de Santa Fe habían iniciado un proceso de convergencia regional) hasta mediados del siglo XIX. Se generaron series de precios e índices de precios de bienes transables (vacunos, cueros, trigo) y de bienes de consumo cotidiano (azúcar, tabaco, yerba, vino, aguardiente, lienzo, sal, sebo y grasa) registrados en fuentes religiosas. El análisis de dicha información ofrece nuevas evidencias y bases explicativas sobre la irrupción de sucesivos ciclos inflacionarios y el quiebre de la economía de Santa Fe desde 1815 hasta 1850.
\end{abstract}

Palabras clave: precios; producción agraria; Río de la Plata; siglo XIX.

Abstract: This study examines price evolution in Santa Fe district (Rio de la Plata) since the late years of colonial domination (when Santa Fe's prices converged with regional prices) to mid-nineteenth century. Monastic sources provided information of prices of commodities (cattle, hides, wheat) as well as prices of consumption goods (sugar, tobacco, yerba mate, wine, aguardiente, salt, grease, tallow, canvas). Long-term prices and price indexes offer new evidence both of inflationary cycles as well as economic breakdown from 1815 to 1850 .

Key words: prices; agrarian output; Rio de la Plata; 19th century.

Recibido: 15 de enero 2016. Aceptado para publicación: 26 de septiembre 2016.

\section{INTRODUCCIÓN}

$\mathrm{L}$

a economía de Santa Fe atravesó sucesivos quiebres económicos y traumáticas coyunturas que afectaron a los actores y a los antiguos ejes ordenadores de la producción y del comercio tardocolonial.

* Consejo Nacional de Investigaciones Científicas y Técnicas.

Am. Lat. Hist. Econ., may.-ago., 2017, pp. 59-92 | DOI:10.28232/alhe.v24i2.746 
En los años que siguieron a la crisis revolucionaria de la primera década del ochocientos (1810-1815) la antigua y próspera elite terrateniente y comercial santafesina, que controlaba el intercambio mercantil entre el Alto Perú, Paraguay y el litoral, asistió primero a la pérdida del mercado de mulas del Potosí, más tarde a la disolución de los negocios de los productores ganaderos asociados a dicho circuito y por fin, a la destrucción de la riqueza ganadera una vez que se instaló la guerra en su propio territorio. Los hacendados santafesinos, considerados en su época como los más ricos del virreinato del Río de la Plata, eran a su vez prósperos comerciantes que construyeron primero sus fortunas en el comercio de intermediación y a finales de la colonia lograron diversificar sus inversiones con la compra de tierras para la cría de mulares y la producción de cueros (Robertson y Robertson, 1950; Tarragó, 1994). Este estudio se propone avanzar en el análisis de la evolución seguida por los precios de los bienes bajo un contexto atravesado por cambios profundos de los actores económicos y de grave inestabilidad e interrupción de los ciclos productivos originados en episodios bélicos.

En un escenario de bajo crecimiento económico y de estancamiento de la frontera productiva, la construcción de series de precios resulta útil para medir indirectamente la profundidad de la llamada gran crisis de la economía de Santa Fe e identificar el grado del impacto de la misma en la evolución de los precios de los bienes en un espacio hasta entonces clave para la economía rioplatense. ${ }^{1}$

La historia de precios cuenta con una agenda metodológica y conceptual renovada por la historiografía europea e internacional que ha puesto interés en el análisis de los orígenes de la divergencia en las condiciones de vida de la población de América Latina, América del Norte y Europa entre los siglos XVI y comienzos del siglo XIX. El actual análisis comparativo de los precios forma parte del estudio sobre la desigualdad en los niveles de vida entre dichos espacios desarrollado por los programas internacionales de medición de las condiciones de vida y los más recientes estudios que han reconstruido series de precios y salarios en América Latina entre los siglos XVI y las primeras décadas del ochocientos (Florescano, 1986; Quiroz, 2005).

La construcción de series de precios y de salarios estuvo alejada hasta etapas recientes de la agenda de la historia económica rioplatense (Gelman, 2006). Sin articularse en un programa de investigación común, las contadas series de precios relativas al caso rioplatense (Broide, 1951; Go-

${ }^{1}$ Es notable la escasez de estudios sobre la evolución de los precios en Santa Fe en el siglo XIX, a excepción de los aportes parciales de Ensinck (1985a), o de las muy tempranas observaciones de Cervera (1907) y de Álvarez (1910). 
rostegui, 1962-1963) registraron limitaciones temporales y espaciales que estuvieron lejos de emprender una agenda común en la construcción de series básicas para el estudio de los mercados regionales en el largo plazo. El análisis de la trayectoria de los precios en Río de la Plata buscó después examinar su evolución en los grandes centros urbanos rioplatenses coloniales en el siglo XVIII. Desde finales de la década de 1980, el trabajo de reconstrucción de los precios tuvo distintos referentes historiográficos. Los estudios sobre precios de bienes en la ciudad de Córdoba en el siglo XVIII se vinculan con el debate sobre la integración económica del espacio colonial en América del Sur. Las investigaciones de L. Johnson (1990) sobre precios, salarios y costo de vida aportaron series de precios de bienes básicos (trigo, carne salada) y de otros bienes de consumo popular (arroz, yerba, azúcar) vigentes en el Buenos Aires virreinal, y permitieron comparar por primera vez la evolución seguida por un bien básico como el trigo de Buenos Aires con el de otras regiones europeas e hispanoamericanas.

Desde inicios de los años de 1990 la historia de precios se instaló como campo de análisis con nuevas evidencias sobre el crecimiento económico y las condiciones de vida en el área rioplatense (Arcondo, 1992). Los aportes de Garavaglia $(1999,2004)$ a la historia rural rioplatense abrieron una nueva discusión sobre los precios de los bienes producidos en las áreas rurales de la provincia de Buenos Aires y sobre el uso de nuevas fuentes privadas (Barba, 1999). El estudio de Gelman (1999), sobre los salarios y los precios en las estancias de Juan Manuel de Rosas, permitió generar series de precios pecuarios de la provincia de Buenos Aires al reconstruir los índices combinados de precios del trigo (Broide, 1951; Gorostegui, 1962-1963). Un trabajo de investigación sobre precios de bienes en Buenos Aires durante el setecientos dio comienzo a la elaboración de canastas de consumo (Cuesta, 2009). Como parte del debate internacional sobre el nivel de vida en Europa y en América hispánica, en la última década se avanzó en la elaboración de series de precios de bienes y en la construcción de canastas de consumo en Río de la Plata mediante el uso de metodologías complejas ensayadas por la historiografía europea para medir la evolución del costo de vida (Allen, 2001; Allen, Murphy y Schneider, 2012; Arroyo, Davies y Van Zanden, 2012; Clark, 2007; Hoffman, 1996; Özmucur y Sevket, 2007; Tandeter y Wachtel, 1992). La investigación de Moraes (2012) sobre los precios agrarios en Montevideo durante la segunda mitad del siglo XVIII, corrobora los postulados sobre el comportamiento estable, e incluso deflacionario, de los precios agrarios rioplatenses en el periodo tardocolonial. En la otra orilla del Plata, la construcción de series de precios se inscribe en una agenda de investigación más amplia en torno al crecimiento económico y la evolución de la desigualdad, la distribución del ingreso y las 
condiciones de vida en los siglos XVIII y XIX (Gelman y Santilli, 2014, 2015; Parolo, 2015).

El caso de Santa Fe, un centro mercantil de estratégica posición dentro del comercio colonial, no había recibido la atención de la historiografía económica hasta hace muy poco. Dos trabajos recientes han reconstruido por primera vez series completas de precios de bienes para todo el siglo XVIII, utilizando fuentes religiosas (Djenderedjian y Martirén, 2013, 2015). Estos estudios han logrado analizar las tendencias seculares de los precios en Santa Fe, una economía interior con un papel clave dentro del espacio colonial rioplatense, detectando movimientos de convergencia entre las series de precios de bienes locales y regionales desde mediados del siglo XVIII y una tendencia ascendente de los precios de los bienes transables a partir de la apertura atlántica en 1780.

\section{FuENTES Y METODOLOGÍA}

Para el examen de la evolución de los precios en Santa Fe de la primera mitad del siglo XIX nos apoyamos en la construcción de series de precios de bienes agrarios que se producían en la campaña rural de Santa Fe (vacunos y cereales) destinados a los mercados regionales e internacionales y de los bienes de uso que intervenían en el consumo cotidiano de la época. ${ }^{2}$ Los precios agrarios se obtuvieron de los Libros de ingresos y de gastos del Colegio Apóstolico San Carlos Borromeo, emplazado a orillas del río Paraná sobre una parte de la antigua estancia jesuítica de San Miguel, una de las áreas rurales más ricas del sur de la provincia de Santa Fe. ${ }^{3}$ Los datos de los precios de los bienes agrarios registrados en San Carlos presentan un conjunto de ventajas. Los registros usados para construir estas series nos permitieron, en primer lugar, trabajar con movimientos alcistas menos intensos que los observados en las grandes ciudades, eludiendo de este modo las distorsiones provocadas por las tensiones inflacionarias que se observan en los centros urbanos en donde además las instituciones estatales intervenían en la fijación de los precios de bienes básicos y en la percepción de impuestos sobre los bienes de consumo directo. A diferencia de los precios obtenidos en ámbitos urbanos, generalmente "administrados" por los cabildos o por las instituciones encargadas del abasto de las ciudades, los precios de los bienes comercializados en ámbitos rurales re-

\footnotetext{
${ }^{2}$ La historiografía europea de las últimas dos décadas aportó nuevos avances metodológicos, véanse Allen, 2001; Feliú, 1991; Llopis y García, 2007; Maluquer, 2013.

${ }^{3}$ Libro de misas, ingreso y gasto del Colegio (1786-1867); Libro de gastos (1782-1826); Libro de gastos (1786-1867); Cuaderno de disposiciones del Colegio de San Carlos de Propaganda Fide (1789-1828), Archivo del Convento Franciscano de San Carlos (en adelante ACSC).
} 
cogían de manera más directa la información producida por los mercados regionales y de larga distancia. En la anotación de los precios de los bienes agrarios (trigo, reses, novillo, vacas, terneras, bueyes) y de los derivados también producidos localmente (sebo, grasa, cueros) la fuente contable no identifica el pago de impuestos. ${ }^{4}$

La contabilidad del convento de San Carlos apunta en forma detallada los precios de los bienes ganaderos (vacas, caballos, cueros, sebo) y agrarios (trigo) que recibían en calidad de donación por parte de los benefactores locales y de los bienes comprados por la institución para el abastecimiento de su casa principal y dependencias (colegio y convento, estancia y chacra de San Lorenzo, calera en la Bajada de Paraná).

Los sistemas de registro de San Carlos no fueron constantes a lo largo del periodo en estudio. ${ }^{5}$ Los asientos semanales en los que se anotaban los gastos y los ingresos fueron reemplazados desde la segunda década del ochocientos por registros mensuales y cuatrimestrales, consignándose en todos los casos los cambios de mes en curso y los balances parciales elaborados por el guardián y aprobados por el síndico del convento. ${ }^{6}$

Desde 1820 y hasta los años de 1840 la economía del convento de San Carlos sufrió una fuerte crisis como consecuencia del repliegue económico de los antiguos benefactores y del derrumbe de las actividades productivas de la región. Con el fin de completar los faltantes informativos del número de registros de bienes pecuarios, anotados entre 1823 y 1842, se tomaron en cuenta los precios de las reses adquiridas por el estado de Santa Fe para el consumo de las tropas del ejército entre 1818 y 1850 . El fondo documental de Contaduría (documentos de data) del estado provincial aportó los datos para completar la serie de precios de los vacunos. Los recibos de compra de reses se emitían semanalmente para todos los cuerpos del ejército, por lo cual esas observaciones periódicas permitieron reconstruir la serie de precios de los vacunos para el periodo, a excepción de contadas lagunas informativas que se salvaron con datos de inventarios post mortem para el periodo de 1823 a $1828 .^{7}$

${ }^{4}$ Cabe observar que tampoco es posible identificar estos costos en los inventarios post mortem que han sido utilizados por la historiografía para recoger información de los precios de los bienes agrarios rioplatenses (Garavaglia, 1999).

${ }^{5}$ Sobre la calidad y uso de los datos de los registros conventuales para la historia de precios, véase Carrara (2008). Sobre el caso rioplatense, Djenderedjian y Martirén (2015).

${ }^{6}$ Se observan cambios de letra, de tinta y de material del papel utilizado, a la par que una gradual caída de la calidad de las anotaciones desde comienzos de la década de 1820 hasta finales de la de 1830.

${ }^{7}$ Recibos de pago de reses a terceros para el consumo del ejército de Santa Fe. Contaduría, Documentos de data, tt. 17-84, 1816-1850, Datos correspondientes al periodo 1823-1828, Archivo General de la Provincia de Santa Fe (en adelante AGPSF). Testamentaria de Nicolás Piedrabuena (1823), Testamentaria de José Carmonas (1824), Testamentaria de Nicolás Molina (1825), Testamentaria de María del Pilar Leyva (1826), Testamentaria de Feliciano Ricardo (1826), Testamen- 
Los registros del convento de San Carlos también incluyen otros insumos informativos indispensables para reconstruir la evolución del costo de vida en Santa Fe en la primera mitad del siglo XIX. Los bienes de consumo cotidiano anotados en la contabilidad de la institución superan la centena y corresponden al diversificado universo de alimentos, vestimenta y de bienes que adquiría la entidad para el consumo de los religiosos. ${ }^{8}$ Las compras de bienes de uso del convento corresponden a precios mayoristas y sólo en una muy menor proporción a precios al detalle. ${ }^{9}$ Se completaron las lagunas informativas del precio del azúcar para el periodo 1828-1836 con datos de una segunda fuente contable: los libros de gastos del convento de San Francisco de la ciudad de Santa Fe, institución establecida en dicha ciudad desde comienzos del siglo XVII. ${ }^{10}$ La contabilidad del convento de San Francisco registró semanalmente los precios de los bienes de uso diario que adquiría la institución, cuya población era menor a la del convento de San Carlos. ${ }^{11}$

A partir de 1820, los sistemas de registro contables del convento de San Carlos mostraron descuido en el método de asiento de los gastos y de cam-

taria Manuel Quiñones (1828), Tribunales, tt. I-IV, Archivo Museo Histórico Provincial de Rosario Dr. Julio Marc (en adelante AMHPR). Expedientes Civiles, Testamentaria de Bernabé Correa (1828), Archivo del Departamento de Estudios Etnográficos y Coloniales (en adelante ADEEC).

${ }^{8}$ Las dietas conventuales seguían las prescripciones de la Orden de San Francisco en América establecidas a mediados del siglo XVIII. El estricto grado de adhesión a las mismas estuvo sujeta a los presupuestos de cada casa religiosa. Los estatutos municipales del convento de San Carlos, aprobados en 1812, instituyeron el consumo cotidiano de vino, chocolate, tocino, legumbres, queso y fruta. Se trataba de una selección de alimentos ajustada a la dieta europea de finales del setecientos. De la guarda de la pobreza y remedio de las necesidades. Véase ACSC, cap. 6, punto 69, fs. 13-15.

${ }^{9}$ El convento de San Carlos compraba parte de los bienes de consumo en los comercios mayoristas de Buenos Aires (azúcar, arroz, chocolate, pimienta, canela, papel, hilo, lienzo, yerba) y de la ciudad de Santa Fe (tabaco, yerba, lienzo, vino, aguardiente, azúcar). Abastecimiento de "géneros" en Buenos Aires (12 de marzo de 1800), Libro de gastos (1786-1867), ACSC.

${ }^{10}$ Libro de gastos (1804-1844) y Libro de gastos (1845-1862), Archivo del Convento de San Francisco de la ciudad de Santa Fe (en adelante ACFSF). El convento de San Francisco adquiría sus bienes de consumo en los comercios de la ciudad. Los precios minoristas de San Francisco son más elevados que los precios mayoristas de San Carlos. Sólo se utilizaron los datos de la contabilidad de San Francisco para la elaboración de los precios índice del azúcar (años 1828-1837); el spread respecto a San Carlos fue de 21.5\% en promedio en el periodo 1820-1827.

${ }^{11}$ La población estable de los conventos comprendía a los religiosos y a un número reducido de legos y de empleados al servicio de las comunidades (cocineros, sirvientes, peones del ganado). En el caso de San Carlos, a estos residentes se les sumaban otros de carácter temporario (peones de obra, albañiles y maestros albañiles, capataces), contratados para la construcción de los edificios del convento, sumando en ciertas etapas 80 a 85 empleados. La población del convento de San Francisco en Santa Fe era más reducida: en 1810 residían quince frailes; el padrón general de la ciudad de Santa Fe levantado en 1816 contó ocho religiosos. Gobierno, t. I, Padrón general del cuartel, núm. 2, ciudad de Santa Fe, levantado el 5 de febrero de 1816, AGPSF. En 1822, una comunicación de la orden de San Francisco al gobierno provincial informó que en San Francisco residían siete frailes, incluyendo el padre guardián. Apéndice 12, Comunicaciones de Religiosos, Gobierno, t. 2 y medio, AGPSF. 
bios en las anotaciones de los ingresos, momento en que también desaparecen los registros de ingresos correspondientes a los rubros sobre limosnas y bienes en especie. En virtud de las limitaciones de los sistemas de registro y de frecuencia de las anotaciones anuales (mínimo de una y máximo de cuatro anotaciones de un mismo bien por año en todo el periodo en análisis), se aceptó incluir datos con una frecuencia mínima y se promediaron los precios con más de una frecuencia anual. Para el armado de las series se tuvo en cuenta el número de años con información, estableciendo un mínimo de $45 \%$ de los años cubiertos (28 años). Las cantidades expresadas en distintas medidas fueron reducidas a unidades homogéneas toda vez que fuese posible. Se descartaron los registros que no discriminaban cantidades y aquellos que consignaban el precio total de la compra de los bienes sin identificar cantidad y precio de cada uno de ellos. La información faltante fue reemplazada mediante interpolación simple (máximo de tres interpolaciones seguidas). Por tratarse de una entidad emplazada en un núcleo urbano, son mínimos los asientos correspondientes a bienes agrarios (trigo, vacas). Los valores de los precios de los bienes están expresados en reales, teniendo en cuenta que el real de a ocho (conocido como peso de plata), fue la unidad monetaria de mayor circulación en Santa Fe durante el periodo en estudio. La moneda de plata acuñada en Potosí circuló en la Santa Fe tardocolonial como principal unidad de cuenta. En 1772 la corona española decretó una primera depreciación, manteniendo la paridad plata-oro en 16 a uno hasta el año 1812, momento en el que se cambió la paridad plata-oro a 17 a uno. En la provincia de Santa Fe se mantuvo la circulación de todo tipo de monedas, aunque el peso de plata sostuvo su carácter de unidad de cuenta y prevaleció por sobre otras monedas de menor valor y sobre el papel moneda emitido en Buenos Aires después de 1820.

Se construyeron series de precios, índices de precios por bien e índices generales: tres series de precios correspondientes a bienes transables (vacunos, cueros y trigo) y nueve series de precios de bienes de consumo y de uso cotidiano (aguardiente, vino, lienzo, grasa, sebo, sal, yerba, azúcar y tabaco). ${ }^{12}$ Nuestra información sobre los consumos alimenticios de los sectores bajos urbanos y rurales da cuenta de una dieta poco variada, centrada en el consumo de carnes rojas (vacunos, ovinos) y de granos (maíz,

\footnotetext{
${ }^{12}$ Se elaboraron índices de precios sobre la base del gasto efectivo de la comunidad religiosa. En una primera prueba se buscó calcular ponderaciones (índice de Paasche), pero sus resultados no fueron satisfactorios. Cabe tener en cuenta las limitaciones propias de la fuente, la cual registra los consumos en el largo plazo de una comunidad de reducidas dimensiones que esporádicamente aumentaba el gasto en años de construcción de instalaciones, de celebraciones religiosas o bien por acontecimientos extraordinarios como el reconocido papel cumplido por el convento de San Carlos para el alojamiento de los soldados y de los heridos del cuerpo de granaderos a caballo tras el combate del 27 de febrero de 1813. Comentarios sobre la metodología para la construcción de los índices de precios véase Djenderedjian y Martirén (2015, nota 26, p. 136).
} 
trigo), complementados por tuberculosas y hortalizas y conformada por sustitutos bienes de primer orden como el vino por otros de menor calidad como el aguardiente y la caña. ${ }^{13}$ En virtud de ello, dejamos fuera de nuestro análisis los variados y selectivos bienes que se sumaban a la dieta de los religiosos regulares (chocolate, pimienta, canela, café, quesos, aceite, sal, vinagre, azafrán, fideos), privilegiando el análisis de la evolución de los precios de aquellos bienes que también eran parte de los consumos masivos de la población rural (aguardiente, vino, textiles de algodón, grasa, yerba, sal, tabaco, azúcar). ${ }^{14}$

\section{DE LA PROSPERIDAD TARDO-COLONIAL A LA GRAN CRISIS DE LA ECONOMÍA DE SANTA FE}

Un ensayo de periodización de la evolución de la economía de Santa Fe reconoce tres ciclos comerciales diferenciados durante el periodo analizado (1790-1850). El primero de ellos, iniciado en el último cuarto del siglo XVIII y cerrado alrededor de 1815, transcurre en una etapa de expansión de la economía de Santa Fe con eje en dos soportes centrales. Por un lado, la producción ganadera con eje en la exportación de cueros vacunos vinculada a la demanda atlántica, al mercado de consumo de vacunos en la región de Misiones y a la producción de mulares con destino en el mercado altoperuano. Desde mediados del siglo XVIII la campaña rural de Santa Fe se había afianzado como espacio de cría ganadera, tanto en las estancias que rodeaban a la ciudad como en las fértiles tierras del sur estratégicamente ubicadas entre los caminos que conectaban Buenos Aires con los mercados del interior, la ciudad de Santa Fe y el corredor de la costa del río Paraná (Álvarez, 1910; Bidut, Caula y Liñán, 1996; Tuella, 1802). La producción de trigo conformaba un segundo y relevante renglón de la economía tardocolonial del área. El cultivo del trigo se dispersaba en las estancias ganaderas de la frontera poblada con vacunos y

${ }^{13}$ Véase el informe del diputado de Santa Fe, Teodoro de Larramendi, ante el Consulado de Buenos Aires en 1795 sobre los consumos alimenticios de la población de Santa Fe, citado en Cervera (1907, t. I, Apéndice, p. 129). Larramendi observaba que "las cosechas actuales se reducen a algunas pocas especies de hortalizas, una mediana cantidad de trigo, garbanzos y naranjas. La más abundante es la que se hace del maíz, calabazas y batatas; de éstas junto con la carne, hace su abasto la plebe para la mayor parte del año y su cultivo es al que se dedica con mayor generalidad y esmero".

${ }^{14}$ En el convento de San Carlos no hay anotaciones de compra de carne, ya que la producción de la estancia abastecía la demanda de la comunidad. Tampoco hay anotaciones de gasto en pan (el convento contaba con una rudimentaria atahona para la producción de harina). Los gastos en pan y en carne fueron anotados como gastos cotidianos en los registros del convento de San Francisco (1806-1850) pero sólo en muy contadas ocasiones encontramos referencias a los precios por unidad. 
mulares desde mediados del siglo XVIII. Tanto en las estancias como en las explotaciones familiares de menores dimensiones se producían granos (fundamentalmente trigo, además de maíz, hortalizas y legumbres) para el consumo familiar. El trigo fue el principal excedente comerciable agrícola con destino al abasto de la ciudad de Santa Fe y de mercados regionales más lejanos como el de Buenos Aires. La segunda y no menos importante clave de la economía provincial fue el comercio de bienes de consumo masivo (yerbas, tabaco, textiles) producidos en Paraguay y en los antiguos territorios de Misiones. Los comerciantes de Santa Fe lograron articular aquel vasto espacio mercantil que incluía las plazas del interior rioplatense (Santiago del Estero, Cuyo, las provincias del norte, Paraguay y Misiones), Chile, Alto Perú y Cuzco. Desde mediados del siglo XVIII los comerciantes de Santa Fe diversificaron sus inversiones mediante la compra de tierras destinadas a la cría de mulares y a la producción de cueros (Canedo, 1993; Djenderedjian, 2008) ${ }^{15}$.

Esta área tuvo un notable crecimiento en el tercer cuarto del setecientos, cuando se concretó la apertura a los mercados atlánticos y americanos, dando lugar a un proceso de valorización de los bienes agrarios (trigo con salida al mercado de la ciudad de Buenos Aires en años de carestía) y de los bienes ganaderos que se producían en el área (cueros, carne, sebo). En Santa Fe este proceso fue acompañado por un aumento de la producción agraria per cápita (trigo y vacunos) y de un incipiente pero sostenido incremento de la población, alentado por el avance de la frontera agraria, tal como se ha señalado recientemente en el reciente estudio de Djenderedjian y Martirén (2015) sobre la evolución de los precios en Santa Fe en el siglo XIX. El crecimiento económico de la región se produjo bajo un escenario de frontera abierta dentro del cual las unidades productivas exhibieron una marcada orientación mercantil. Bajo ese contexto se dieron mejoras de la productividad y del producto per cápita (verificables por el crecimiento de la recaudación decimal de la jurisdicción), un marcado descenso de los precios entre 1760 y 1780 y un movimiento de convergencia entre las series de precios locales (cueros, vacas, sebo) con los de Córdoba y de Buenos Aires.

A finales de la etapa tardocolonial (1780-1810) este ciclo de crecimiento continuó su movimiento pero a un ritmo más bajo y con leve caída del producto (detectada en la recaudación decimal del período 1790-1810). ${ }^{16}$

${ }^{15}$ Las tres estancias de propiedad de Francisco A. Candioti, ubicadas en los distritos de la periferia de Santa Fe (Monte de los Padres, Rincón de Dávila y Arroyo Hondo), contribuyeron con cuantiosos planteles de equinos y vacunos para el aprovisionamiento de las tropas del general Manuel Belgrano en la campaña de Paraguay (Iriondo, 1871).

${ }^{16}$ Diezmos de granos y de cuatropea. IX-13-3-3, Testimonio de remate de diezmos, Santa Fe (1750-1800); IXX -7-3-2. Cuadrante de Diezmos (1800-1810), Archivo General de la Nación (en 
Impulsados por la demanda, los precios de los bienes producidos localmente iniciaron una trayectoria de ascenso y de mayor divergencia con los precios de los bienes de consumo que se producían en el espacio regional americano.

Aquella larga etapa de crecimiento se cerró en 1810 y se agotó definitivamente a mediados de la segunda década del ochocientos, cuando Santa Fe no sólo perdió el control en la intermediación de bienes de consumo con los mercados rioplatenses virreinales, sino que su territorio sufrió la ocupación militar por parte de los ejércitos de Buenos Aires y los de Artigas, lo que provocó la destrucción de su riqueza ganadera. Aquellas coyunturas críticas que tuvieron por epicentro el ciclo bélico de 1815-1820, impactaron negativamente en la actividad económica provincial (Fradkin y Ratto, 2014). Los productores asistieron a la depredación y al agotamiento de sus planteles ganaderos, en tanto que las explotaciones familiares especializadas en la producción de trigo fueron golpeadas por las levas que dejaron sin brazos y sin dirección a las pequeñas unidades agrícolas.

Como consecuencia de la militarización de la campaña, el estado provincial convalidó desde entonces un largo ciclo de presión sobre los planteles ganaderos para el mantenimiento de las milicias locales. Desde 1815 la economía de Santa Fe sufrió una severa y prolongada retracción, signada por el agotamiento de los stocks vacunos y por las dificultades para reorganizar el perfil productivo ganadero con destino al mercado atlántico. El gasto militar consumió recursos, lo que dejó como resultado un déficit crónico en las finanzas del nuevo estado provincial que fue solventado mediante nuevos impuestos indirectos sobre el consumo, la producción y el comercio, esto afectó no sólo la relación del gobierno con los distintos sectores productivos y mercantiles, sino con el mayoritario conjunto de la población rural. ${ }^{17}$

Asimismo se redefinieron las relaciones entre los nuevos poderes provinciales y la esfera eclesiástica, lo que desdibujó el papel de la estructura eclesiástica regular como oferente de crédito al comercio y a los productores locales (Martínez, 2012). La interrupción del comercio atlántico tras la guerra con Brasil (1826-1828), la reanudación de la guerra con Buenos Aires (1829-1830) y la peor sequía del siglo XIX (1829-1832), postergaron la recuperación de los stocks ganaderos de la provincia. ${ }^{18}$ En este escenario de

\footnotetext{
adelante AGN). Serie Contaduría, t. 13 (1800-1806), AGPSF, y Djenderedjian (2008).

${ }^{17}$ Los nuevos gravámenes y escalas de impuestos establecidos en 1821 y 1834-1835 (derechos de importación de bienes de consumo locales y extranjeros, derechos de salida para las lanas y los cueros ovinos, derechos de piso y de carretas) convivieron con los diezmos, sisa, alcabala, derecho de pulperías, sellos y guías tardo-coloniales (Álvarez, 1943).

${ }^{18}$ Las crisis climáticas prolongadas (reducción del promedio de lluvias, aumento de periodos secos y calurosos) que se sucedieron en el área pampeana (sequías e inundaciones) ocuparon la
} 
caída del producto, de repliegue de la frontera agraria los ciclos inflacionarios acentuados por factores externos recorrieron la economía provincial hasta finales de los años de 1830. En particular, la población rural y urbana se vio afectada por severos cambios en la estructura de los precios alimenticios: si bajo la economía tardocolonial regía una estructura asimétrica del movimiento de los precios de los dos bienes, que ordenaban el patrón nutricional de la población (trigo y carne), en la etapa posrevolucionaria se perdió la posibilidad de compensar las alzas bruscas de los precios de los cereales, sustituyendo el consumo de cereales por carne a bajo precio.

La mejoría de la producción vacuna y triguera de Santa Fe recién dio señales firmes en los años que siguieron al bloqueo anglo-francés de 1838 . En la década de 1840 la economía de la provincia de Santa Fe respondió positivamente a la irrupción de ciclos cortos de expansiones de la demanda de bienes ganaderos para el mercado internacional y de la demanda de granos para el creciente mercado porteño (Garavaglia, 1999). Se abrió entonces un tercer ciclo comercial motorizado por dos vectores: el crecimiento de los saldos exportables provinciales (cueros vacunos, ganado en pie, lanares, maderas, sebo) y la recuperación del protagonismo de Santa Fe en la comercialización de la producción del interior rioplatense. En este último segmento, varios elementos jugaron a favor de la intensificación de los intercambios entre Santa Fe y otras plazas mercantiles. Uno de ellos tuvo origen en la estratégica reducción de los costos de fletes gracias a la regularización y organización de un sistema de transporte fluvial a través del eje del Paraná iniciada en la década de 1830, facilitando la vinculación de las economías regionales con el comercio atlántico. En segundo lugar, creció el protagonismo de Rosario en la exportación de bienes producidos en la provincia y en el negocio de reexportación de la producción del interior (Frid, 2013). El crecimiento del volumen comercializado por Rosario se convirtió en un incentivo esencial para la economía local, conformando un mercado de consumo y generando flujos de circulante que en parte encontraron destino en la producción agraria del sur de Santa Fe.

\section{LOS PRECIOS AGRARIOS}

\section{Una difícil trayectoria: los precios ganaderos en Santa Fe}

La primera serie de precios de bienes primarios que exploramos es la de los vacunos. La contabilidad del convento de San Carlos provee infor-

tercera parte del periodo en análisis, afectando el desarrollo del ciclo agrario en la jurisdicción (Ardissone, 1937; Politis, 1984). 
mación sobre la evolución de los precios ganaderos en Santa Fe desde la última década del siglo XVIII hasta comienzos de $1820 .{ }^{19}$ Durante ese periodo los ingresos de la congregación provenían de los donativos periódicos otorgados por benefactores locales en productos agrarios (limosna de trigo) y ganaderos (vacas de cría, novillos, cueros). El convento contaba además con una estancia en la que se criaban planteles vacunos para el consumo de la entidad y para el mercado. ${ }^{20}$ Tras el derrumbe de la producción ganadera (y de las limitadas posibilidades de sus actores para reorganizar los circuitos productivos y recuperar rentabilidades) los precios de los planteles ganaderos dejaron de registrarse en el convento de San Carlos después de 1818.

A fin de completar los datos de los precios del ganado vacuno después de 1820, se utilizó una segunda serie documental: los recibos de compras de reses (vacas y novillos) para el consumo del ejército de Santa Fe emitidos entre 1819 y 1850 por el estado provincial. ${ }^{21}$ Dado que la contabilidad estatal registra lagunas para los estratégicos años de 1823-1828, la información faltante se cubrió con datos de precios de inventarios post mortem para el mismo periodo. ${ }^{22}$ La serie de precios de los vacunos (véase gráfica 1) representa los valores promedio durante aquel largo periodo que media entre finales del siglo XVIII y mediados del ochocientos. Para la construcción de esta primera serie tomamos en cuenta las dos variedades vacunas con mayor representatividad en las fuentes religiosas y estatales consultadas, las vacas y los novillos. ${ }^{23}$ Con ellas elaboramos dos series de precios y una tercer serie promedio que combina los precios de ambas expresados todos en precios índices tomando como base el año $1801 .{ }^{24}$ Se atendió de

\footnotetext{
${ }^{19}$ Libro de ingresos, núm. 8 (1786-1867), ACSC. Las anotaciones de los precios de las vacas y de los novillos están anotadas en los registros anuales de ingresos del convento comprendidos en el periodo 1790-1817.

${ }^{20}$ En la década de 1820 el promedio de vacunos (vacas de cría, novillos, bueyes y lecheras) de la estancia del convento alcanzó los 430 animales, por encima del promedio de esos años (315 animales vacunos por explotación). Cuaderno de disposiciones del Colegio de San Carlos de Propaganda Fide (1789-1828), ACSC.

${ }^{21}$ Recibo de compra de 30 reses para el Escuadrón de Dragones en la estancia de Malaquías Duarte (19 de febrero de 1821). Contaduría, t. 23, leg. 11, AGPSF.

${ }^{22}$ Mientas que los inventarios post mortem de la época asentaban con detalle las múltiples categorías que organizaban la cría de vacunos (vacas de cría, vacas grandes, reses chicas, cabezas de la yerra pasada, vacunos de dos años para arriba, lecheras, bueyes, terneras), los libros del convento resumieron las categorías ganaderas en un número menor de variedades: vacas (vacunos, reses, vacas lecheras), novillos (novillos, novillos de tres años, novillos de cuatro años), terneras y bueyes.

${ }^{23}$ La serie documental correspondiente a las compras de vacunos para el ejército sólo incluyen las categorías reses y novillos. Los precios de los novillos dejaron de registrarse en los libros manuales de contaduría del estado provincial partir de 1843.

${ }^{24}$ Tomamos como base una fecha previa al gran cambio operado en la economía rioplatense en 1810. Se eligió para ello 1801, un año que consideramos normal para la época, es decir, sin alteraciones climáticas graves ni interrupciones del comercio exterior.
} 
este modo al hecho de que existían precios diferenciales entre las distintas variedades de vacunos criollos rioplatenses, si bien dicho spread fue menor al que se registró en la segunda mitad del ochocientos tras la introducción de animales refinados en las praderas rioplatenses. ${ }^{25} \mathrm{El}$ consumo de planteles durante el ciclo 1815-1825 fue indiscriminado, agotando todos los stocks de reserva (bueyes, vacas lecheras, terneros, toros y por supuesto, novillos), reduciendo diferencias de calidades y de peso dentro de la oferta ganadera alimenticia.

Las curvas de precios de las dos variedades vacunas siguen un movimiento solidario a lo largo de todo el periodo, si bien se verifican diferencias especialmente en años críticos. La evolución de la serie de precios vacunos promedio de Santa Fe describe una trayectoria de marcada estabilidad durante la etapa tardocolonial. Vemos que desde inicios de la década de 1790 se registra una caída continuada de los precios pecuarios de Santa Fe por el exceso de oferta y de acumulación de stocks generado por el cierre de la salida atlántica. ${ }^{26}$ Este movimiento, que también ha sido verificado para el caso de los precios pecuarios de la campaña de Buenos Aires, continuó vigente hasta el año $1809 .{ }^{27}$ Vemos también que durante esta primera etapa los novillos siguen de cerca a los precios de las vacas (sólo caen por debajo del valor índice inicial de 1790 en la primera década del ochocientos, aunque escoltando el movimiento de precios promedio tras el ciclo de sequía e inundaciones de 1803-1804).

El segundo periodo de observación arranca en la segunda década del siglo XIX y se cierra en el primer lustro de la década de 1830. Con los cambios de rumbo operados desde 1810, la estabilidad tardocolonial dejó lugar a un sostenido movimiento de ascenso de los precios ganaderos con alzas abruptas verificadas entre 1818 y 1826 y bajas coyunturales por la interrupción de la salida de saldos exportables durante los años de bloqueo comercial (1826-1828). La serie promedio de los vacunos de Santa Fe muestra en

${ }^{25}$ En la etapa previa a la implantación del refinamiento vacuno verificado en la segunda mitad del siglo XIX, los diferenciales de precio entre las variedades del ganado criollo se sustentaban en el peso y en la edad del animal. Cabe señalar que las diferencias de precios entre novillos y vacas podían tender a equipararse, por ejemplo, cuando se trataba de novillos de cinco años cuyo peso podía alcanzar 280 o hasta $300 \mathrm{~kg}$, apenas debajo del peso promedio de una vaca de cría $(350 \mathrm{~kg})$.

${ }_{26}$ Sobre la oferta de vacunos en Santa Fe Agustín de Iriondo, diputado por Santa Fe en el Real Consulado de Buenos Aires, expresaba en 1799 que "tanto en [la] Banda del Paraná como en esta se va aumentando el ganado vacuno de modo que si las pases [sic] se dilatan para poder hacer corambres no se sabrá lo que se ha de hacer y llegará el caso que no produzca lo que cuesta su cuidado en esta jurisdicción donde nace más de los que se consume" (12 de octubre de 1799), Sala IX, Real Tribunal del Consulado, Diputaciones en Tucumán, Santa Fe y Corrientes, 1794-1810, Santa Fe, t. IV, núm. 15, f. 111, AGN.

${ }^{27}$ Sobre la caída de precios de los vacunos en Buenos Aires entre 1791 y 1808, véase Garavaglia (1999). 


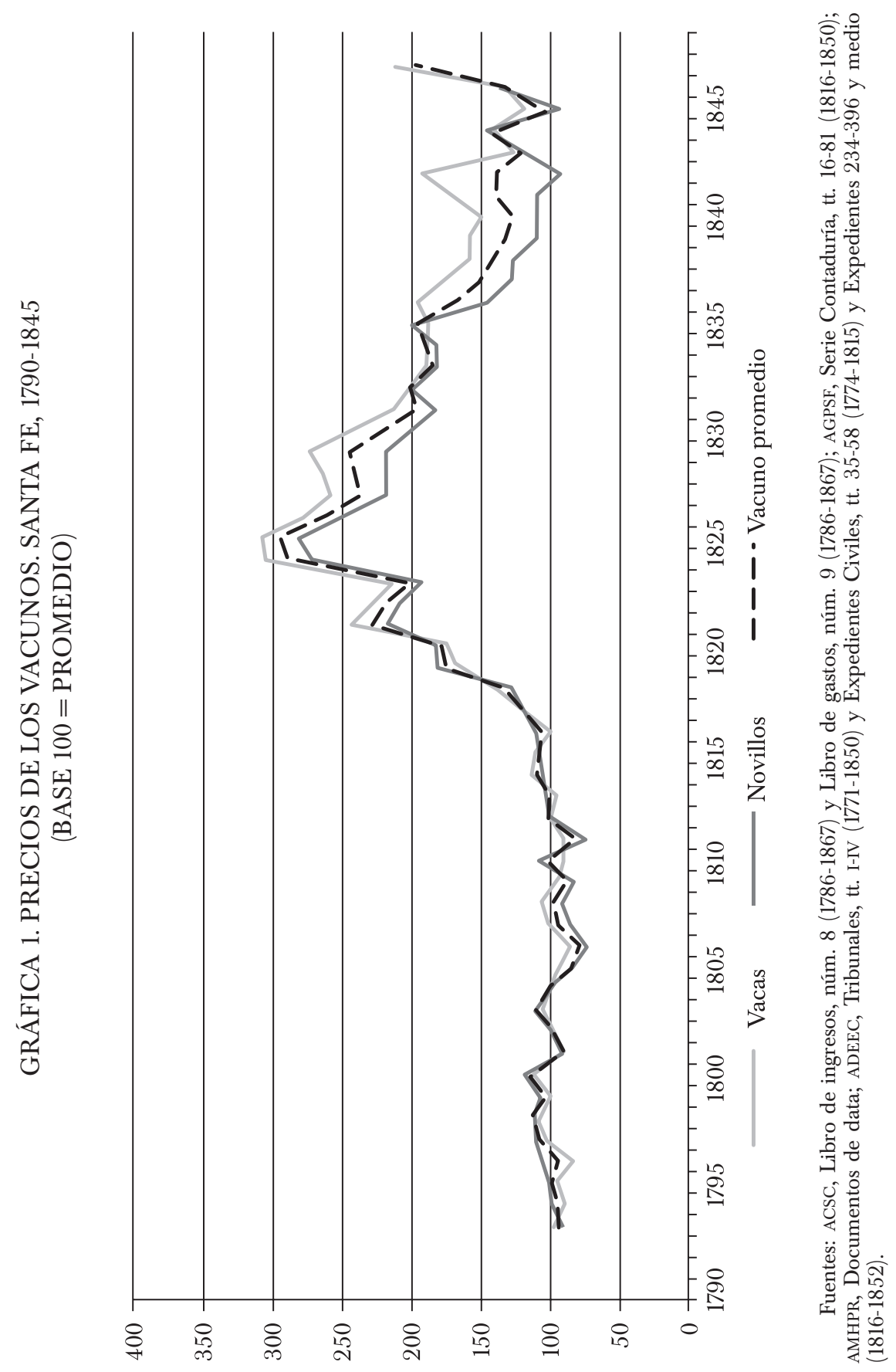


efecto un primer movimiento de ascenso hasta 1815 que sigue en paralelo la apertura comercial atlántica iniciada en 1810 pero la trayectoria que sigue desde entonces estuvo lejos de reflejar los beneficios de la nueva orientación mercantil que se proyectaron sobre las economías de la provincia de Buenos Aires y aun de Entre Ríos. Por el contrario, los precios de los vacunos de Santa Fe emprenden una vertiginosa carrera alcanzando en el periodo 1821-1826 los índices más altos de la primera mitad del siglo XIX, con valores que triplicaban los de comienzos del siglo XIX.

Si la cronología de las escaladas de los precios de los vacunos provinciales exhibe una marcada afinidad con los saltos de precios registrados para los vacunos bonaerenses en el periodo 1817-1826, las bases que sustentan ambos movimientos resultan bien diferentes. ${ }^{28}$ Mientras que el alza pronunciada del precio de los vacunos de la campaña bonaerense reflejó el crecimiento exorbitante de la demanda de ganado engordado con destino a los saladeros y a la exportación de cueros, en Santa Fe primaron las coyunturas de quiebre bélico, las prácticas de presión estatal sobre los planteles vacunos y equinos y el saqueo sistemático de las fuerzas militares en pugna, presionando gravemente sobre la oferta. La voracidad de los ejércitos consumió en breve lapso los capitales de pequeños y grandes propietarios, no sólo reduciendo el stock vacuno total sino agotando el stock de reserva con el que anteriormente se compensaba la oferta ganadera en sus distintas tipologías (novillos, terneros, vacas de cría). ${ }^{29}$ A esta alteración de los ciclos ganaderos se sumaron fenómenos climáticos adversos como el de la gran sequía de 1828-1832, la mayor crisis climática rioplatense registrada en la primera mitad del ochocientos.

Estos eventos externos demoraron la recuperación del ciclo productivo ganadero pero no explican todas las claves de la crisis de la producción ganadera local y del retraso relativo de la economía provincial. Mientras que otras economías vecinas reconstruyeron sus planteles (como fue el caso de Entre Ríos) o bien aprovecharon las ventajas de la expansión de la frontera ganadera asociada al mercado atlántico (Buenos Aires), Santa Fe perdió competitividad cuando desaparecieron las ventajas que ordenaban su negocio ganadero en la etapa colonial (exportación de mulares al Alto Perú y de vacunos con destino a Misiones y al mercado atlántico) tras los

${ }^{28}$ El estudio de Garavaglia (1999) sobre el mercado consumidor de Buenos Aires y la crisis de escasez de reses en 1817-1818 examina detenidamente el movimiento de precios vacunos en la campaña bonaerense.

${ }^{29}$ Un vecino de Santa Fe reclamaba en 1816 al gobierno provincial por la pérdida de su pequeño capital en animales, "habiéndome hallado retenido en el Ejto. de esta ciudad cdo. el de Buenos Aires ocupo esta plaza en el campamento de la chacra de Andino en donde tenía mi familia y los pocos animales que me abian quedado que solo se contenían en tres lecheras y tres vaquillonas y dos bueyes que mataron para consumir" (31 de octubre de 1816), Contaduría, t. 17, leg. 10, f. 1295, AGPSF. 
nuevos condicionamientos externos derivados de la reorientación de la estructura mercantil al mercado atlántico. A mediados de la década de 1830 la producción ganadera de Santa Fe logró lentamente recomponer el abasto de las tropas y el consumo de la población, tal como lo sugiere la caída de la serie de los novillos desde mediados de la década de 1830, movimiento que difiere de la tendencia amesetada (véase gráfica 1) pero de precios altos que presenta la serie de las vacas en el mismo periodo.

Aunque con precios más ajustados al rumbo que por entonces seguían los bienes ganaderos rioplatenses, las señales de recuperación de la producción ganadera santafesina, verificables en las dimensiones y en la tasa de crecimiento de sus saldos exportables ganaderos (cueros, sebo), se mostraban todavía muy limitadas durante la década de 1830 (Rosal, 2003; Rosal y Schmit, 2004). No obstante, la mejora de las rentabilidades durante este ciclo de precios altos de los vacunos favoreció la consolidación del stock ganadero local en los años siguientes, más allá de la coyuntural caída de los precios de la producción y de los bienes exportables ganaderos (vacunos, novillos, cueros) durante los años del bloqueo francés (1838-1841).

En el cambio de década la economía de la provincia de Santa Fe respondió positivamente a la irrupción de ciclos cortos de expansiones de la demanda de bienes ganaderos. Tanto el aumento de los promedios de animales vacunos por explotación (que en esos años es de 350, muy cerca del promedio general del periodo 1825-1850, calculado en 327 vacunos por unidad de producción) como el crecimiento del número de cueros exportados desde la provincia son indicativos de la firme (aunque todavía modesta) recuperación de la producción vacuna santafesina: la exportación per cápita de cueros de Santa Fe se duplicó en relación con la década anterior pero a una tasa todavía menor que la de Entre Ríos y Buenos Aires (Frid, 2013). En la serie de precios índice (véase gráfica 2) reconocemos la solidaridad de los precios de los cueros de Santa Fe con los precios promedio de los vacunos desde los años tardocoloniales hasta el quiebre de 1820, momento a partir del cual los cueros se desprenden hasta alcanzar alzas críticas (en 1822 cuadruplican el valor índice de 1801), expresando el efecto combinado de la crisis ganadera local y la tracción de la demanda internacional. ${ }^{30} \mathrm{El}$ destacado descenso que registran entre 1833 y el primer

\footnotetext{
${ }^{30}$ Los precios de los cueros contabilizados en el convento no incluyen el costo de flete terrestre. Conocemos el precio del costo del flete fluvial (Santa Fe-puerto de Buenos Aires) correspondiente a los años de 1816 (dos reales por cuero) y de 1843 (1.5 reales por cuero). Luis María Aldao contra Juana Larramendi por cobro de pesos, Expedientes Civiles, t. s. n., año 1826, documento núm. 305, fs. 201-358, ADEEC. Para algunos años $(1809$, 1816, 1843) fue posible controlar los precios registrados por el convento con los de otras fuentes (juicios comerciales, archivos privados), encontrando en todos los casos marcada afinidad entre ellos. Cuentas particulares de Manuel Ignacio Diez de Andino, Colección Diez de Andino, Carpeta XI, Trigo, s. f., AGPSF; Luis María Aldao contra Juana Larramendi por cobro de pesos, Expedientes Civiles, t. s. n., año 1826, docu-
} 
lustro de 1840 (más allá de la caída coyuntural provocada por el bloqueo francés) dan cuenta de la gradual mejora de la oferta ganadera santafesina.

Un itinerario afín siguieron dos subproductos de origen vacuno con demanda sostenida en los mercados locales (grasa y sebo) e internacionales (sebo). Desde sus inicios el convento de San Carlos recibía periódicas donaciones de sebo que la institución procesaba dentro de su establecimiento rural para producir grasa. Después de 1815 los datos de ingresos en concepto de sebo disminuyeron, mientras que en su lugar crecieron las compras de grasa para el consumo alimenticio de la comunidad. Los precios de la grasa registraron un alza pronunciada a comienzos de la década de 1820 , y en 1830, por efecto de la fuerte sequía del periodo. La posterior demora de la recuperación ganadera provincial (verificada en la caída de la exportación de cueros desde Santa Fe) compensó el movimiento de ascenso del precio de la grasa de los años de $1820 .^{31}$

\section{El trigo y la economía de Santa Fe}

La producción triguera de Santa Fe prosperó desde las primeras décadas del siglo XVIII en los distritos cercanos a la costa y más tarde en las tierras ubicadas dentro de la estrecha franja productiva que separaba la frontera indígena con el curso fluvial del Paraná desde el sur hasta el norte de la provincia. La producción de granos hizo base primero en el corredor triguero de la costa aventajado por la abundancia de humedad y los bajos costos de flete: las tierras cercanas a Capilla del Rosario y Pavón en el sur, y de Coronda al norte del Carcarañá concentraron gran parte de la oferta cerealera. Desde finales del siglo XVIII el trigo se afianzó en los terrenos de estancias del interior y en las chacras periurbanas de la capital con el objetivo de ampliar la oferta de trigo para la ciudad de Santa Fe, centro urbano que contaba a principios del siglo XIX con una población que si bien era numéricamente limitada -4500 habitantes según el recuento de Féliz de Azara relevado en 1801- constituía una demanda estable de consumo de harinas y de pan.

Aquel enclave agrario se nutrió de un núcleo heterogéneo de productores, tanto por fuera como por dentro de la estancia. ${ }^{32}$ Un sector mayo-

mento núm. 305, fs. 201-358, y Autos obrados por los herederos de D. Félix Constanzo contra D. Juan G. Puyana cobrándole cantidad de pesos. Expedientes Civiles, t. s. n., año 1849, documento núm. 385, fs. 278-246, ambos en ADEEC.

${ }^{31}$ Sobre los efectos de las sequías en el precio de la grasa y sobre la relación entre los precios de los cueros y la grasa, véase Cuesta (2009).

${ }^{32}$ Desde finales de la década de 1790 las cifras de los diezmos granos se registra un crecimiento constante de la producción en la jurisdicción decimal de Santa Fe (Coronda, Arroyos, 


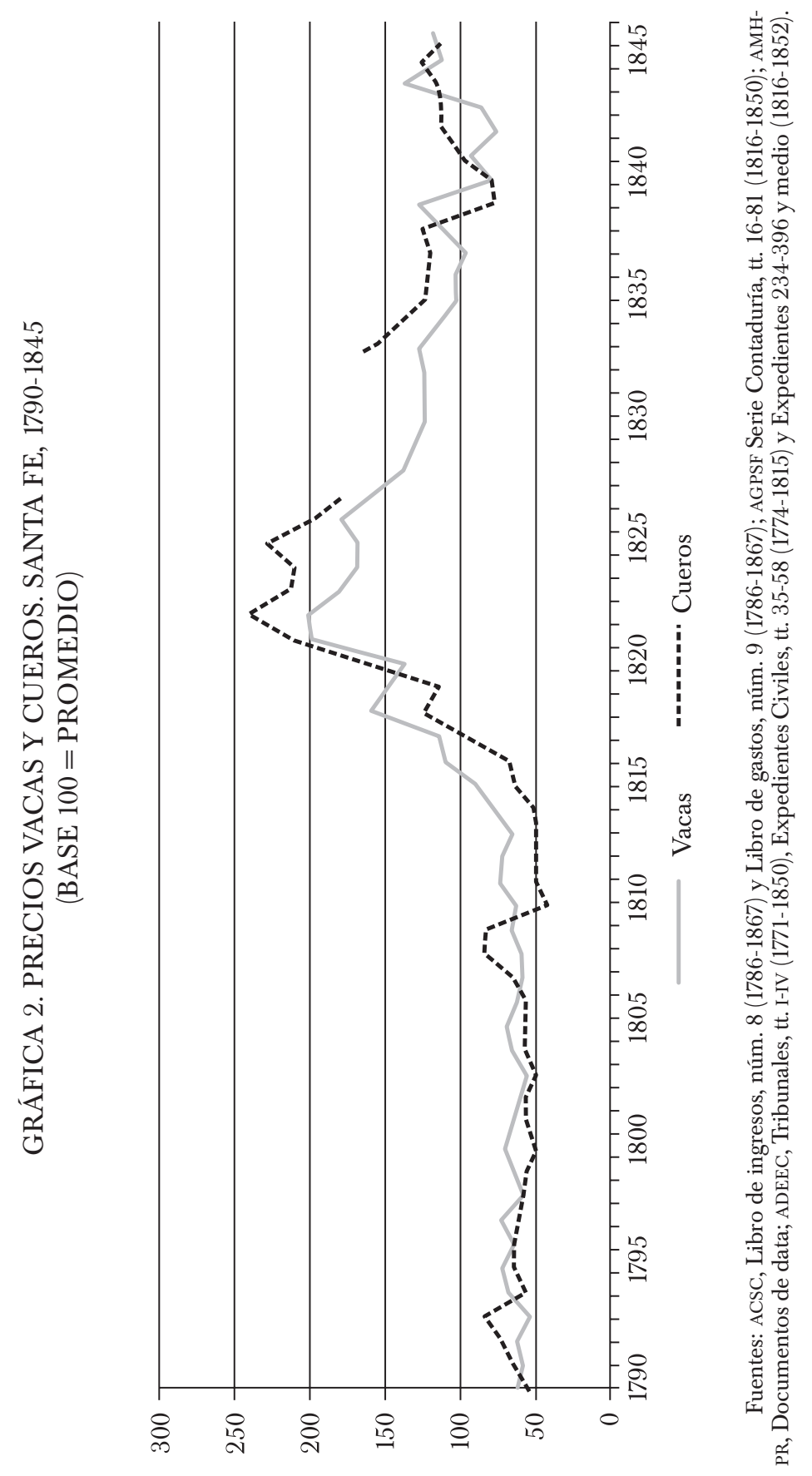


ritario de aquel padrón de productores estaba representado por explotaciones familiares con disponibilidad de mano de obra a bajo costo y niveles de productividad relativa. Esta agricultura dio lugar a un temprano esquema productivo no limitado a una agricultura de subsistencia, sino también orientado a la producción de saldos exportables que se colocaban en los mercados locales y más distantes como el de Buenos Aires, cuya población crecía desde finales del setecientos a ritmos mayores que la oferta. En 1815, el área de los Arroyos, cuyas tierras se extendían desde el Arroyo del Medio al río Carcarañá, alojaba a más de 180 unidades de labradores que se especializaban en el cultivo del trigo, parte de las cuales colocaban su producción en aquellos mercados. La producción de trigo tuvo en la estancia ganadera un segundo ámbito de producción. Las unidades más capitalizadas crecieron bajo un patrón de inversión en infraestructuras (galpones, cercos, atahonas) y en instrumentos agrícolas (arados, hoces, azadas). Uno de los rasgos más explícitos del grado de especialización que alcanzó el corredor cerealero santafesino fue la adopción de una pauta de inversión tecnológica orientada a mejorar el segmento de labranza. La incorporación de tecnologías de hierro (arados con reja de hierro y timón) aparece constatada en la década de 1770 en los inventarios post mortem del sur de Santa Fe.

Para construir la serie del trigo se tomaron los precios del cereal anotados en la contabilidad del convento de San Carlos. El cereal ingresaba periódicamente al convento de en calidad de limosna recogida en las estancias y chacras de las cercanías y después vendía a los acopiadores y comerciantes locales. ${ }^{33}$ Debido a que la fuente no permite discriminar los costos de flete, la serie obtenida no incluye este coste. ${ }^{34}$

Chacras y Ciudad). El área sembrada a mediados del siglo XVIII fue estimada en 1200 hectáreas (Djenderedjian, 2008). En 1816-1818, la superficie bajo cultivo se mantenía en esos rangos. Libro manual de cargo y data, Contaduría, tt. 13-18 (1800-1817), AGPSF.

${ }^{33}$ El convento de San Carlos contó desde sus inicios con licencia diocesana para recoger bienes de limosna. Para la recolección y acarreo del producto de la limosna de trigo el convento contrataba peones que acompañaban a uno o dos religiosos en las salidas. Véase Barral (2007) sobre la organización de la empresa de la limosna en el Río de la Plata tardo-colonial.

${ }^{34}$ Las fuentes conventuales sólo discriminaron los costos del flete terrestre del trigo en 1794 . En esa ocasión, el costo de acarreo desde San Lorenzo hasta la ciudad de Santa Fe fue de cuatro reales por fanega de trigo. Quince pesos por conducir 30 fanegas de trigo a Santa Fe, julio-agosto de 1794, Libro de gastos, núm. 9, 1786-1867, ACSC. En 1807, el propietario de la estancia San Miguel (ubicada a orillas del río Carcarañá en el sur de Santa Fe) calculó un costo de cinco reales por fanega de trigo para el acarreo terrestre de 62 fanegas de trigo desde su estancia a la ciudad de Santa Fe, ubicada a $130 \mathrm{~km}$ al norte de su propiedad. Cuentas particulares de Manuel Ignacio Diez de Andino, Colección Diez de Andino, Carpeta XI, Trigo, leg. 48, 5 fs., AGPSF. En el libro de gastos se anotaban globalmente los "gastos de conducción de trigo" imputados al pago de los salarios y dietas de los peones que participaban en la recolección de la limosna. Tampoco hay menciones a los impuestos exigidos en las operaciones de compra y de venta (alcabalas) y de exportación establecidos por el estado provincial. 
A diferencia de los precios de los vacunos y de la carne, solidarios con los ciclos comerciales portuarios, los precios del trigo de Santa Fe estuvieron sujetos a las coyunturas de la oferta local y a la demanda del mercado de Buenos Aires. En los últimos años del periodo tardocolonial (1780-1810) los índices del trigo de Santa Fe siguieron de cerca la trayectoria alcista verificada en el área rioplatense a finales del siglo XVIII, si bien cabe advertir que los mismos presentaban valores elevados aun en una etapa en la cual el costo de los factores era todavía favorable, por cuanto existía acceso a mano de obra esclava en las estancias y mano de obra familiar en las explotaciones agrícolas del cordón triguero del Paraná.

El alto precio del trigo de Santa Fe de ese periodo tiene relación con la debilidad de la demanda local cuyo mayor eje ordenador estaba en el mercado de la ciudad capital santafesina (la población de la ciudad de Santa Fe creció muy lentamente a lo largo del periodo). La llegada de los trigos santafesinos al mercado porteño sólo se producía bajo episodios críticos de escasez de trigo en la ciudad capital, teniendo en cuenta los elevados costos del flete terrestre en la época. ${ }^{35}$

En el ciclo que se abre en 1815 asistimos al periodo de quiebre de las matrices que hasta entonces habían ordenado la producción triguera de Santa Fe. La guerra fue el escenario primario de la desorganización de la producción agraria, golpeada por los saqueos de los ejércitos porteños y artiguistas y por la militarización de la mano de obra rural entre 1815 y 1825. La década de 1820 profundizó finalmente la crisis del antiguo enclave granario. En parte la caída de la producción triguera se potenció por los efectos negativos de sucesivos episodios climáticos (ciclo de sequía y peste de roya de trigo entre 1819 y 1822 y la gran sequía de 1829-1832) que redujeron la producción de Santa Fe a sus mínimos seculares. ${ }^{36} \mathrm{La}$ antigua ecuación agraria perdió validación por lo menos hasta comienzos de los años de 1840 al caer muchas de las bases que la sustentaban: la reducción de la superficie cultivable a favor del incremento de terrenos para la cría ganadera fue el resultado del alza del costo de la mano de obra y del crédito para un negocio de alto riesgo y de rentabilidades fluctuantes. El abandono del sector por parte de los operadores locales que controlaban el circuito de la intermediación de granos fue un episodio más de aquella gran crisis (Djenderedjian, 2008).

\footnotetext{
${ }^{35}$ Sobre las dimensiones del mercado del trigo en el Buenos Aires de finales de la colonia, véanse Garavaglia (1999) y Johnson (1990).

${ }^{36}$ Sobre la sequía de 1817, señalaba M. I. Diez de Andino (1931) en agosto de ese año "cayó un aguacero [...]; no se dice que haya causado mayor daño en los sembrados, habiendo sufrido casi un año sin llover [...]. De tarde en tarde una corta lluvia, por lo que muchos labradores no han sembrado trigos y el que ha valido 9 y 10 pesos, aunque no ha faltado, lo mismo el maíz y todas las legumbres; igualmente las carnes gordas aunque caras, el sebo y la grasa.”
} 
Los precios del trigo de Santa Fe (véase gráfica 3) describen un movimiento de marcada volatilidad y de fuertes fluctuaciones a lo largo de todo el periodo, con un desvío estándar (15.3) muy superior al verificado por los vacunos (5.02) a lo largo de toda la etapa. Estos fenómenos refieren a las dificultades que presentó la actividad agraria para su subsistencia y continuidad y del cambio operado en la estructura asimétrica de los precios de la carne y del trigo tras la instalación de movimientos de alza continua y simultánea de bienes básicos en la alimentación de la población. Los años de las dramáticas alzas del precio del trigo (1818-1825 y 1827-1833) coincidieron con ciclos de escaladas inflacionarias y de carestía de la carne y de subproductos necesarios para la alimentación como la grasa, afectando negativamente las condiciones de vida de la población.

Tras la salida de la gran sequía en 1833, los precios del trigo de Santa Fe lograron estabilizarse gracias a una paulatina mejora de la oferta. En la década de 1840 el trigo santafesino volvió a participar del mercado bonaerense alentado por el bajo costo del flete fluvial (cinco veces menor al precio del transporte terrestre), la mayor disponibilidad de mano de obra rural y al alza creciente de la demanda local en los últimos años de la década de 1840. Estos incentivos favorecieron la recuperación de un área de especialización triguera que sobre todo cobró entidad en las unidades productivas en la campaña del sur de Santa Fe, a juzgar por el creciente espacio que la actividad fue ganando tanto de las pequeñas unidades productivas como de las explotaciones mayores, fenómeno acreditado en el aumento del número de instrumentos de labranza, animales de tiro e infraestructuras para el almacenamiento de cereales. ${ }^{37}$ Junto con la estabilización de la oferta agraria y la paulatina reorganización de los mercados del trigo santafesinos (agentes, logística, crédito) consolidada en el último lustro de los años de 1840, los precios del trigo provincial siguieron un camino de mayor convergencia con los de Buenos Aires. De todos modos, la producción de cereales en Santa Fe recién emprendió la vía del crecimiento a partir de 1860 y de la mano de la mejora de la productividad agraria con la introducción de tecnologías y de nuevas pautas productivas traccionadas por la colonización.

\footnotetext{
${ }^{37}$ En las estancias de los dos distritos del sur de Santa Fe (Coronda y Arroyos) se producía maíz y trigo. Hay constancias de construcción de infraestructuras mínimas que están presentes en las testamentarías del periodo en estudio (granero, horno de pan, pozo de balde) en el departamento Rosario situado en el sur provincial. Inventario de bienes de Francisco Tello (1841), Tribunales, t. IV, AMHPR. En Rosario se constata la venta de equipos simples de labranza (como arados con reja de hierro, azadas). Inventario de bienes de José Tiscornia (1847), Tribunales, t. IV, AMHPR.
} 


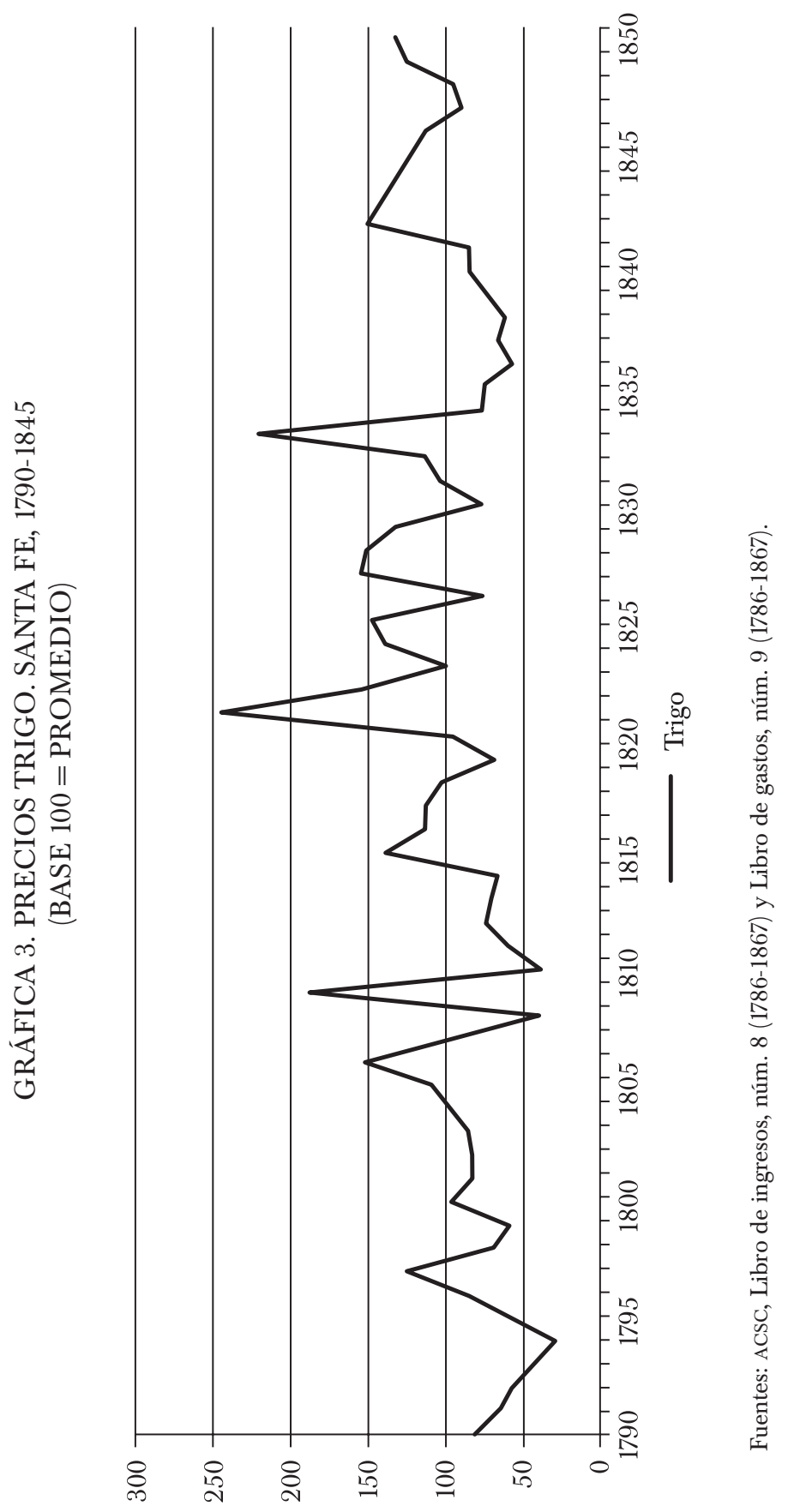




\section{LOS PRECIOS DE LOS BIENES DE CONSUMO EN UNA ECONOMÍA EN DIFICULTADES}

Santa Fe había ocupado un lugar clave dentro del espacio productivo y mercantil integrado que vinculaba el área peruana, la producción del interior rioplatense, Paraguay y los mercados atlánticos. Dentro de aquel vasto circuito de bienes y servicios, Santa Fe constituía un eje de conexión de bienes ultramarinos y de producción regional de alto volumen y con anclaje en el consumo popular, tanto de la que provenía del área surandina (aguardiente, textiles, azúcar) como de Misiones y Paraguay (yerba mate, tabaco, textiles). La pérdida del mercado alto-peruano y de Paraguay desmanteló la articulación mercantil secular entre mercados interiores y puertos y redujo la disponibilidad de acceso de metálico. La apertura de rutas ultramarinas y la consolidación de un nuevo esquema productivo pecuario construyeron las matrices de la nueva orientación de la economía posrevolucionaria rioplatense, generando economías exportadoras de mayor rentabilidad basadas en la especialización y la conexión con los mercados ultramarinos.

Las nuevas orientaciones comerciales de los estados posrevolucionarios se sustentaron en la expansión mercantil y en el consumo de bienes populares (yerba, tabaco, harina). El comercio de bienes importados fue crucial para los aparatos fiscales provinciales, basados en la expansión mercantil resultante del crecimiento de la producción exportable y del aumento de los consumos. Tras la pérdida del papel articulador de la comercialización de la producción Paraguay y del Litoral, los bienes comestibles importados de consumo masivo (yerba, tabaco, harinas) ocuparon un lugar estratégico para el fisco provincial. La reforma fiscal de 1821 elevó los derechos de entrada del tabaco de Paraguay a diez reales por arroba y a doce reales el tercio de yerba, en tanto que caían los aforos de los mismos productos que se importaban de Brasil (Ensinck, 1985b; Schmit, 2011).

Los estudios que han examinado la evolución de los bienes de consumo regionales e importados sostienen que los precios de los bienes con fuerte participación dentro de los consumos domésticos experimentaron primero un ciclo de retracción (desde 1810 hasta mediados de la década de 1820), registrando luego fuertes fluctuaciones como resultado de ciclos cortos de alza originados por turbulencias temporarias en la oferta de bienes regionales originadas primero por la guerra revolucionaria y a partir de 1820 por las interrupciones temporarias del comercio (bloqueos y conflictos bélicos internos) (Assadourian y Palomeque, 2003). En el largo plazo que va desde la revolución a las décadas de 1840 y de 1850 , la trayectoria de los precios de los bienes de consumo importados fue marcadamente descendente. No obstante, faltan investigaciones sistemáticas 
que examinen críticamente las dimensiones y la intensidad de la demanda de bienes importados en los mercados provinciales del Litoral, sobre todo después de 1820.

En Santa Fe es posible identificar estos fenómenos aunque con ciertas particularidades propias de la evolución de la economía local. Es muy notoria la convergencia del movimiento de precios verificada en la última etapa colonial, con alzas leves de los precios de los bienes exportables bajo un contexto de estabilidad relativa de los bienes de consumo masivo (azúcar, yerba, tabaco, textiles). Después de la revolución, tanto los precios de los bienes transables como los de los bienes de consumo describieron un vertiginoso trayecto y un cambio de rumbo de tendencia, atravesada por ciclos inflacionarios en los que se combinaron explosivamente alzas de precios de los bienes básicos (carne, trigo) y de los bienes de consumo popular.

La evolución seguida por el índice de precios de bienes de consumo de Santa Fe constata un periodo de estabilidad en los años que precedieron al ciclo de alza iniciado en 1809-1811 (véase gráfica 4). A partir de entonces siguió una etapa de alzas con cotas máximas a comienzos y a finales de la década de 1820, en tanto que en las dos décadas siguientes impactan los bloqueos y las interrupciones al comercio. El cuadro general es en parte coincidente con las versiones que postulan una trayectoria divergente entre los precios de los bienes de consumo y los de las materias primas exportables, que registran una evolución alcista a partir de $1810 .^{38}$ $\mathrm{Al}$ interior del índice aparecen, no obstante, diferencias marcadas en el comportamiento de ciertos bienes en algunos trayectos de esta larga etapa y en particular durante las dos primeras décadas posteriores a la revolución. En los precios de los bienes de consumo masivo (yerba, azúcar, tabaco, lienzo de algodón) se produjeron fuertes alzas en la década que siguió a la revolución como resultado de la separación del Paraguay. ${ }^{39}$ La yerba paraguaya fue reemplazada por yerba brasileña, de menor precio y calidad, a raíz de los conflictos abiertos con el gobierno de Asunción, conflictos que tensionaron las relaciones de los comerciantes santafesinos que comenzaron a importar azúcar y yerba de Brasil para colocarlas en el mercado local. ${ }^{40}$

\footnotetext{
${ }^{38}$ Sobre el descenso de los precios de los bienes de consumo y la apertura mercantil atlántica iniciada en 1810, véase Newland (2000).

${ }^{39}$ Los cambios en los circuitos del comercio de la yerba se constatan desde 1820. El comerciante santafesino Manuel Ignacio Diez de Andino (Diez de Andino, 1931) señalaba en 1820 que llegaban a Santa Fe barcos desde Montevideo y desde la localidad de Paraná con yerba del Paraguay. Sobre la producción de yerba en Paraguay, véase Djenderedjian (1998).

${ }^{40}$ A principios de la década de 1820 Diez de Andino (Diez de Andino, 1931) observaba los efectos negativos del alza de precios de la yerba paraguaya sobre el comercio a larga distancia. Sobre el comercio de la yerba en el Río de la Plata, véase Palomeque (1989).
} 
Un renglón de peso en el gasto del convento de San Carlos recayó en la compra de yerba, aguardiente y tabaco, artículos de consumo cotidiano de la población rural rioplatense que la entidad proveía gratuitamente a los trabajadores rurales y a los que se ocupaban de la construcción del establecimiento (Djenderedjian y Martirén, 2015; Frid, 2016). La yerba tenía fuerte participación en la canasta de consumo de amplios sectores de la población rural. En la observación de la evolución del índice de la yerba vemos cómo después de casi dos décadas de estabilidad (1788 a 1807), el precio de este bien de consumo asciende paulatinamente, verificando saltos de crecimiento importantes entre 1819 y mediados de 1840. Si bien los movimientos alcistas (tanto de la yerba como del tabaco) a lo largo de todo el periodo tienen correlación con eventos externos extraordinarios y con ciclos inflacionarios internos a la crisis de la economía santafesina, es necesario analizar otras variables de peso, tales como los efectos de la pérdida de control por parte de los agentes e intermediarios mercantiles de Santa Fe de aquel gigantesco negocio de distribución de la yerba del Paraguay y de Misiones en los mercados del interior rioplatense (Santiago del Estero, Tucumán, Cuyo, Buenos Aires), Chile y Alto Perú. La salida de los operadores santafesinos y la llegada de la yerba de Brasil a través de circuitos comerciales bonaerenses, tuvo un impacto adverso no sólo en la recaudación fiscal del nuevo estado provincial, sino también en el aumento de los márgenes de intermediación que se trasladaban al precio del bien. ${ }^{41}$

La comercialización del tabaco chocó con dificultades similares a las encontradas en el caso de la yerba, a raíz de las interrupciones esporádicas del comercio con Paraguay a comienzos de la década de 1820 (beneficiando la introducción del tabaco tarijeño y del Brasil) y hasta los años de 1830, cuando Paraguay recuperó alguna porción del mercado de la yerba y del tabaco en los puertos del litoral. ${ }^{42}$

Los precios de los tejidos, del azúcar, aguardiente y vino siguieron por su parte un movimiento hacia la baja a lo largo del periodo, tendencia que también acompañaron los textiles de algodón. Algunos ejemplos muestran el giro operado sobre la oferta local después de 1810. Desde 1815 las com-

${ }^{41}$ Los cambios en los derechos de entrada y de salida al tabaco y a la yerba establecidos por la reforma fiscal provincial de 1821 gravaron fuertemente la yerba y el tabaco del Paraguay, elevando el precio interno de dichos bienes y reduciendo el papel de los comerciantes de Santa Fe en los circuitos mercantiles regionales. Los derechos de importación al tabaco fueron suprimidos en 1839. Registro Oficial de la Provincia de Santa Fe, t. I, 1815-1847, Santa Fe, 1888, p. 61; Ensinck (1985a).

${ }^{42}$ Gasto en quince arrobas de tabaco de Paraguay y de dos arrobas de tabaco de Brasil (26 de mayo de 1812 a 30 de noviembre de 1812) y Gasto en catorce arrobas de yerba del Paraguay (22 de abril de1822 a 19 de octubre de 1822), Libro de gastos del Colegio de San Carlos, núm. 9 (1786-1867), ACSC. 


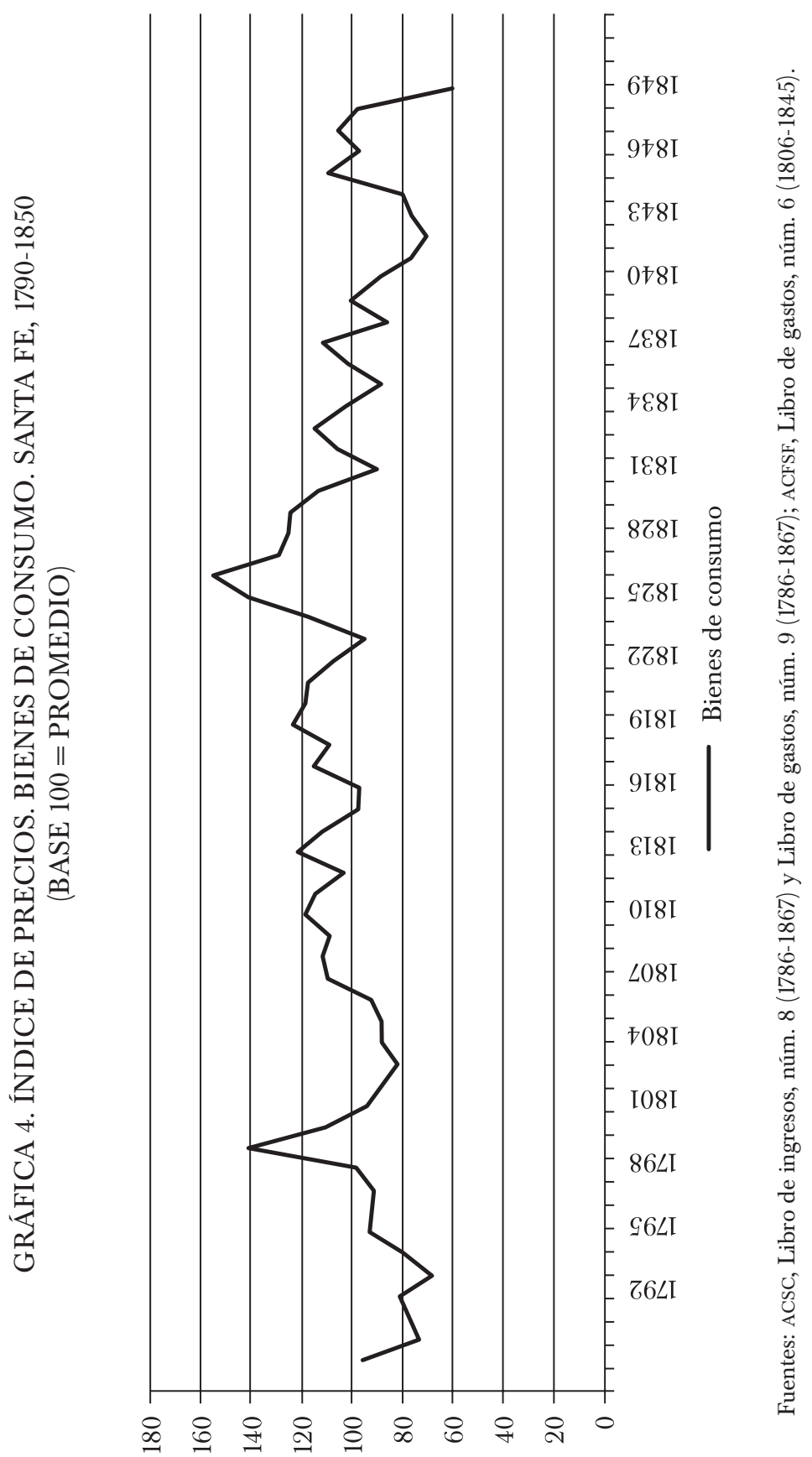


pras de vino español se redujeron en el convento de San Carlos, ganando terreno el vino de Mendoza, más barato que los de Málaga y de Cataluña que se consumían en el convento durante los años de prosperidad tardocolonial. La apertura comercial rioplatense afectó los circuitos de otros conjuntos de bienes de consumo masivo que tenían origen en mercados más lejanos, tales como el azúcar de Perú que llegaba al área rioplatense desde Chile. ${ }^{43}$ Tras la interrupción definitiva del circuito chileno y la apertura mercantil atlántica, bajo control de los comerciantes porteños desde la segunda década del ochocientos, se reemplazó el azúcar peruana por la brasileña, de menor costo que la anterior. ${ }^{44}$

Otro componente de relevancia en el gasto de los conventos lo conformaban los textiles. La vestimenta de los religiosos y del personal de servicio constituía un rubro fijo dentro del gasto anual de las casas religiosas. En los libros contables de San Carlos se anotaron las calidades y variedades de textiles que circulaban por el espacio rioplatense de la última etapa colonial: tucuyos de lana de oveja producidos en las antiguas Misiones de Chiquitos, lienzo de Paraguay y de Misiones y textiles ultramarinos (lienzo de Galicia y lienzo portugués, lienzo de brin, bayeta de Irlanda). Las calidades y origen de los textiles de algodón y de lana anotados por el convento en las décadas posrevolucionarias no permiten verificar procesos de sustitución por textiles europeos importados, tal como lo ha sugerido una parte de la historiografía (Newland y Gallo, 2004). Por el contrario, las anotaciones apuntan a la continuidad de las pautas de consumo de textiles de la población rural (bayetas, cordobanes, ponchos de Corrientes y de Santiago) y de la población en general (lienzo de lino y de algodón de Catamarca y de Córdoba en reemplazo del algodón alto-peruano), bienes cuyos precios también se orientaron a la baja al promediar el ochocientos. ${ }^{45}$

A finales de 1830 la economía provincial inició un camino de reacomodamiento de sus matrices bajo un contexto de paz. Los precios de los productos ganaderos estabilizaron su tendencia decreciente en tanto

\footnotetext{
${ }^{43}$ Se trataba de azúcar producida en los valles de la costa peruana y que ingresaban al mercado rioplatense colonial vía Chile (Assadourian y Palomeque, 2003). Las distintas calidades y orígenes de los vinos en Libro de gastos del Colegio de San Carlos, núm. 9 (1786-1867), ACSC.

${ }^{44}$ Gasto en seis arrobas de azúcar blanca (1 de octubre de 1823 a 1 de octubre de 1824). Libro de gastos del Colegio de San Carlos, núm. 9 (1786-1867), ACsC.

${ }^{45}$ En el convento de San Francisco se inscribían sistemáticamente las compras de textiles y de vestimenta para los frailes y para los criados y en el cierre del balance anual se registraban las prendas adquiridas durante el periodo y los nombres de sus destinatarios; Gasto en 85 varas de lienzo de tucuyo de Misiones ( 5 de junio de 1808 a 1 de octubre de 1804); Gasto en 190 varas de algodón de Cochabamba (junio de 1807); Gasto en ocho varas de lienzo de Galicia (noviembre de 1807); Gasto en ocho varas de lienzo de algodón de Córdoba (22 de septiembre 1815 a 19 de abril de 1816); Gasto en lienzo portugués (21 de junio de 1817 a 19 de septiembre de 1817). Libro de gastos del Colegio de San Carlos, núm. 9 (1786-1867), todas en ACSC. Sobre el mercado de textiles coloniales, véase Garavaglia (1986).
} 
que los bienes de consumo resistieron en niveles siempre mayores a los de la etapa tardocolonial, alentados por alzas bruscas de las variaciones de los precios de consumo durante el bloqueo anglo-francés (1838-1839), esporádicas turbulencias políticas (1841) y breves ciclos especulativos ante interrupciones de los circuitos comerciales fluviales (1846-1847). ${ }^{46}$ Tras la reorganización del perfil productivo orientado a la exportación de bienes pecuarios y la mejora de la balanza comercial provincial, Santa Fe logró reorientar lentamente la economía provincial e incrementar sus exportaciones tanto de animales en pie para satisfacer la demanda del mercado de porteño como de cueros vacunos y lanares, tal como lo confirman los estudios que se han ocupado de examinar los flujos comerciales y la integración económica rioplatense y de medir la evolución de los saldos exportables santafesinos con destino a la Aduana de Buenos Aires. ${ }^{47}$

\section{CONCLUSIONES}

Los precios de Santa Fe en la primera mitad del siglo XIX permiten observar las dificultades atravesadas en la etapa posrevolucionaria por una de las economías tardocoloniales más prósperas de Río de la Plata. Santa Fe aporta un caso de interés en el análisis del devenir de las economías del interior rioplatense tras la apertura comercial iniciada en la segunda década del siglo XIX. Nos permite evaluar también los efectos de los cambios estructurales que operaron en la etapa posrevolucionaria sobre economías conectadas con mercados y espacios productivos regionales distantes y con la economía atlántica. Desde mediados del siglo XVIII la economía de Santa Fe había alcanzado una marcada integración con los mercados del interior rioplatense y los regionales con los cuales sostenía un intenso contacto mercantil, asociando parte de su producción de bienes agrarios (cría de mulas), al intercambio comercial con dichos mercados. Logró también integrarse con éxito al ciclo de valorización de bienes con demanda ultramarina en el caso de los bienes ganaderos (cueros, sebo, grasa) y de cereales (trigo) que se colocaban esporádicamente en el mercado de Buenos Aires. En esta etapa de crecimiento de la economía y de la población los precios de los bienes transables producidos en Santa Fe respondieron

\footnotetext{
${ }^{46}$ Tal como lo expresaba bien el encargado de asentar los gastos del convento de San Francisco tras la invasión de las tropas del general Lavalle a la ciudad de Santa Fe en el turbulento mes de septiembre de 1841, "la Revolución aumenta el gasto" (18 de septiembre de 1841), Libro de gastos, núm. 4 (1806-1844), ACSC.

${ }^{47}$ Entre 1846 y 1848 Santa Fe había aumentado el flujo comercial a Buenos Aires a un ritmo de 10\% anual (Rosal, 2003; Rosal y Schmit, 2004).
} 
al proceso de valorización expresadas en alzas leves pero sostenidas en los últimos años de la etapa colonial.

Tras el advenimiento de la guerra posrevolucionaria, del derrumbe de la producción de bienes que la vinculaban con los mercados de larga distancia y de la salida de los circuitos mercantiles regionales, la economía de Santa Fe cambió de rumbo atravesando una ardua y prolongada etapa de crisis y de pérdida de competitividad de su producción.

Durante este prolongado periodo de retracción, Santa Fe recorrió un camino divergente respecto a los espacios de la economía rioplatense del periodo que habían logrado integrarse a la demanda internacional. Así, mientras que en Buenos Aires las bruscas alzas de precios de los bienes agrarios que recorrieron la etapa 1818-1826 respondieron a la presión de la demanda, el ciclo inflacionario de Santa Fe tuvo origen en el derrumbe de la oferta generada tras el agotamiento de los stocks vacunos y la desorganización de los ejes que sostenían la tradicional producción triguera provincial. En efecto, los recurrentes ciclos de estrés que dieron lugar a la pérdida de la producción y de la reserva del stock ganadero vacuno local, impulsaron el alza de los precios de los bienes ganaderos (vacas, cueros, sebo, grasa) y sólo al final del periodo en estudio se anota un movimiento de mayor convergencia con los precios rioplatenses.

Los precios del trigo se mantuvieron altos a lo largo del periodo tardaron en descender en Santa Fe por razones coyunturales y estructurales. Después de 1820, la producción triguera no logró recuperarse bajo las mismas claves que habían facilitado su desarrollo en los años de la prosperidad tardocolonial cuando la pequeña producción familiar ordenaba la mayor parte de la producción especializada en trigos de pan con alta demanda en los mercados regionales. La alteración de los costos de los factores iniciada en 1820 desfavoreció el ingreso de nuevos inversores a un negocio de altos riesgos en un mercado de incertidumbre y elevados costos de transporte. Durante buena parte del periodo, aquella explosiva combinación de bruscas y simultáneas variaciones alcistas, tanto de los bienes transables como los de consumo, impactaron con fuerza en las condiciones de vida y el bienestar de la población. En efecto, el derrumbe de la economía y de la producción agraria tuvo por resultado el quiebre de la tradicional estructura asimétrica de los precios agrarios a partir de la cual las periódicas carestías provocadas por el alza del precio del trigo se compensaban con bajos precios de la carne. Desde entonces y hasta por lo menos mediados de 1840, rigió un patrón de alzas simétricas de los precios de los bienes, tanto de los agrarios como de los de consumo cotidiano (yerba, tabaco, aguardiente).

En los años de 1840 se reiteraron los ciclos de variaciones bruscas de los precios agrarios cuando se sumaron coyunturas negativas en las eco- 
nomías cercanas y de fuerte conexión con Santa Fe, en particular aquellas derivadas del ciclo inflacionario monetario bonaerense del primer lustro de la década de 1840. La ecuación productiva agraria tuvo cambios a favor en la década de 1840. El rubro más rentable del negocio rural del periodo, la cría de vacunos y la exportación de cueros inició una lenta etapa de recuperación. Por entonces también las mejoras en el sistema de navegación fluvial costera, en embarcaciones con mayor volumen de carga, redujeron en una quinta parte los costos de flete de trigo a Buenos Aires. No obstante, la inelasticidad de la oferta triguera del sur de Santa Fe, limitada por sus condicionantes estructurales (mano de obra, límites espaciales de la frontera productiva, inversiones), apenas estuvo en condiciones de responder esporádicamente a los incentivos de la creciente demanda generada por el gran mercado de consumo porteño. Por el mismo camino de consolidación de su oferta ganadera y triguera, se retomaron los circuitos que permitieron aprovechar la renta de localización de aquella región clave en la economía rioplatense y se recuperó el papel de Santa Fe dentro del vasto espacio comercial que conectaba la producción del interior con las mayores plazas mercantiles rioplatenses.

\section{REFERENCIAS}

Allen, R. C. (2001). The great divergence in European wages and prices from the Middle Ages to the First World War. Explorations in Economic History, 38(4), 411-447. DOI: 10.1006/exeh.2001.0775.

Allen, R. C., Murphy, T. y Schneider, E. (2012). The colonial origins of the divergence in the Americas: A labor market approach. The Journal of Economic History, 72(4), 863-894.

Álvarez, J. (1910). Ensayo sobre la historia de Santa Fe. Buenos Aires: Establecimiento Tipográfico E. Malena.

Álvarez, J. (1943). Historia de Rosario. Buenos Aires: 1943.

Arcondo, A. (1992). El ocaso de una sociedad estamental. Córdoba entre 1700 y 1760. Córdoba: Universidad Nacional de Córdoba.

Ardissone, R. (1937). Datos históricos acerca de las precipitaciones pluviales en la zona de Buenos Aires. Desde el siglo XVI hasta 1821 (pp. 198-211). Buenos Aires: Imprenta Coni.

Arroyo, L., Davies, E., van Zanden, J. (2012). Between conquest and independence: Real wages and demographic change in Spanish America, 1530-1820. Explorations in Economic History, 49(2), 149-166. DOI: 10.1006/exeh.2001.0775

Assadourian, C. S. y Palomeque, S. (2003). Las relaciones mercantiles de Córdoba (1800-1830). Desarticulación y desmonetización del mercado interno colonial en el nacimiento del espacio económico nacional. En M. A. IRIGOIN y R. ScHMit, La 
desintegración de la economía colonial. Comercio y moneda en el interior del espacio colonial (1800-1860) (pp. 151-226). Buenos Aires: Biblos.

AzARA, F. DE (1943). Memoria del estado rural del Río de la Plata en 1801. Buenos Aires: Bajel.

Barba, F. E. (1999). Aproximación al estudio de los precios y salarios en Buenos Aires desde fines del siglo XVIII hasta 1860. La Plata: Universidad Nacional de La Plata.

Barral, M. E. (2007). De sotanas por la Pampa: religión y sociedad en el Buenos Aires rural tardo-colonial Prometeo: Buenos Aires.

Bidut, V., Caula, E. y Liñán, N. (1996). Productores y producción en el partido de Rosario de los Arroyos a comienzos del siglo XIX. Papeles de Trabajo, 1(1), CESOR, Facultad de Humanidades y Artes, Universidad Nacional de Rosario.

Broide, J. (1951). Evolución de los precios pecuarios argentinos en el periodo 18301850. Revista de la Facultad de Ciencias Económicas, 4(32), 113-183.

Canedo, M. (1993). La ganadería de mulas en la campaña bonaerense. Una aproximación a las estrategias de producción y comercialización en la segunda mitad del siglo XVIII. En R. MANDRINI y A. Reguera, Huellas en la tierra: indios agricultores y hacendados en la pampa bonaerense (pp. 147-160). Tandil: Instituto de Estudios Histórico-Sociales Prof. Juan C. Grosso.

Carrara, A. (2008). Para uma história dos preços do periodo colonial: questoês de método. Locus: Revista de História, 14(1), 163-194. Recuperado de http://www.uff. br/locus/files/2010/02/76.pdf

Cervera, M. M. (1907). Historia de la ciudad y provincia de Santa Fe (tt. I y II). Santa Fe: La Unión de Ramón Ibáñez.

Clark, G. (2007). The long march of history: Farm wages, population and economic growth, England 1209-1869. Economic History Reviewe, 60(1), 97-136. Recuperado de http://faculty.econ.ucdavis.edu/faculty/gclark/papers/echr2006.pdf

Cuesta, M. (2009). Precios, población, impuestos y producción. La economía de Buenos Aires en el siglo XVIII. Buenos Aires: Temas Grupo Editorial.

Diez de Andino, M. I. (1931). Diario de don Manuel Ignacio Diez de Andino. Crónica santafecina, 1815-1822. Argentina: Junta de Historia y Numismática Americana/ Publicaciones de la Filial Rosario.

Djenderedjian, J. (1998). Una reevaluación del peonaje por deudas. El caso de la producción yerbatera paraguaya a inicios del siglo XIX. Boletín del Instituto de Historia Americana y Argentina Dr. Emilio J. Ravignani, 16-17, 85-122. Recuperado de http:// ravignanidigital.com.ar/_bol_ravig/n16_17/n1617a04.pdf

DJENDEREDJIAN, J. (2008). La agricultura pampeana en la primera mitad del siglo XIX. Buenos Aires: Siglo XXI.

Djenderedjian, J. y Martirén, J. L. (2013). Los precios de los bienes en las fronteras bravías del Río de la Plata colonial: Santa Fe durante la primera mitad del siglo XVIII. América Latina en la Historia Económica, 20(2), 35-64. DOI: http://dx.doi. org/10.18232/alhe.v20i2.538 
Djenderedjian, J. y Martirén J. L. (2015). Precios, producto agrario y niveles de vida en las fronteras rioplatenses, 1700-1810; una nueva mirada sobre el crecimiento económico tardo-colonial. Revista Historia Económica/Journal of Iberian and Latin American Economic History, 33(1), 123-152. DOI: https://doi.org/10.1017/ S0212610915000051

Ensinck, O. L. (1985a). Historia económica de la provincia de Santa Fe. Rosario: Universidad Nacional de Rosario.

EnsincK, O. L. (1985b). Recursos fiscales en la provincia de Santa Fe. Derechos de Aduana y Presupuestos (siglo XIX). Revista de la Junta Provincial de Estudios Históricos de Santa Fe, 56, 45-49.

FELIÚ, G. (1991). Precios y salarios en la Cataluña moderna, t. I: Alimentos (pp. 13-16). Madrid: Banco de España.

Florescano, E. (1986). Precios del maíz y crisis agrícolas en México, 1708-1810. México: Era.

Fradkin, R. y RATTO, S. (2014). Presiones estatales y respuestas sociales: la experiencia del Ejército de Observación sobre Santa Fe, 1815-1820. En D. SANTILli, J. Gelman y R. FRADKIN (comps.), Rebeldes con causa: conflicto y movilización popular en la Argentina del siglo XIX (pp. 81-120). Buenos Aires: Prometeo.

FRID, C. (2013). Producción agraria y crecimiento económico en el sur de Santa Fe (1840-1860). En C. FRID y N. LANCIOTTI, De la expansión agraria al desarrollo industrial. La economía de Santa Fe entre 1850 y 1870 (pp. 17-48). Rosario: Prohistoria.

FRID, C. (2016). La evolución de los salarios en una economía en crisis: Santa Fe en la primera mitad del siglo XIX. XV Congreso de Historia Agraria de la SEHA, Lisboa.

Garavaglia, J. C. (1986). Los textiles de la tierra en el contexto colonial rioplatense: ¿una revolución industrial fallida? Anuario IEHS: Instituto de Estudios Histórico-Sociales, $1,45-87$.

Garavaglia, J. C. (1999). Pastores y labradores de Buenos Aires: una historia agraria de la campaña bonaerense, 1700-1830. Buenos Aires: Ediciones de la Flor.

Garavaglia, J. C. (2004). La economía rural en la campaña de Buenos Aires vista a través de sus precios: (1756-1852). En R. Fradkin y J. C. Garavaglia, En busca de un tiempo perdido. La economía de Buenos Aires en el país de la abundancia 1750-1865 (pp. 107-158). Buenos Aires: Prometeo.

Gelman, J. (1999). Las condiciones del crecimiento estanciero en el Buenos Aires de la primera mitad del siglo XIX. Trabajo, salarios y conflictos en las estancias de Rosas. En J. Gelman, J. C. Garavaglia y B. Zeberio (comps.), Expansión capitalista y transformaciones regionales: relaciones sociales y empresas agrarias en la Argentina del siglo XIX. Buenos Aires: La Colmena/Universidad del Centro de la Provincia de Buenos Aires.

Gelman, J. (2006). Introducción. Un balance con luces y sombras. En J. Gelman (comp.), La historia económica en la encrucijada. Balances y perspectivas (pp. 9-25). Buenos Aires: Prometeo.

Gelman, J. y Santilli, D. (2014). Mar de fondo. Salarios, precios y los cambios en las condiciones de vida de los pobladores de Buenos Aires en una época convulsa, 
1810-1870. En D. SAntilli, J. Gelman y R. FradKin (comps.), Rebeldes con causa: conflicto y movilización popular en la Argentina del siglo XIX (pp. 121-148). Buenos Aires: Prometeo.

Gelman, J. y Santilli, D. (2015). Salarios y precios de los factores en Buenos Aires, 1770-1880: una aproximación a la distribución funcional del ingreso en el largo plazo. Revista de Historia Económica/Journal of Iberian and Latin American Economic History, 33(1), 153-186.

Gorostegui, H. (1962-1963). Los precios del trigo en Buenos Aires durante el gobierno de Rosas. Anuario del Instituto de Investigaciones Históricas, 6, 141-161.

Hoffman, P. T. (1996). Growth in a traditional society. The French countryside 1450-1815. Princeton: Princeton University Press.

IRIOndo, U. DE (1871). Apuntes para la historia de Santa Fe. Santa Fe: Imprenta del Pueblo.

Johnson, L. (1990). Salarios, precios y costo de vida en el Buenos Aires colonial tardío. Boletín del Instituto de Historia Argentina y Americana Dr. Emilio Ravignani, 2, 133-157.

Llopis, E. y García, H. (2007). Cost of living and wages in Madrid, 1680-1800. En Unpublished paper presented at the Seventh European Historical Economics Society Conference. Suecia: Lund.

MALUQUeR, J. (2013). La inflación en España: un índice de consumo, 1830-2012 (Estudios de Historia Económica, núm. 64). Madrid: Banco de España.

MarTínez, I. (2012). El caudillo y el párroco: centralización política y eclesiástica durante la autonomía santafesina. 1815-1852. Boletín del Instituto de Historia. Argentina y Americana Dr. Emilio Ravignani, 34, 11-45.

MoraEs, M. I. (2012). Las economías agrarias del litoral rioplatense en la segunda mitad del siglo XVIII: paisajes y desempeño (Tesis doctoral). Universidad Complutense de Madrid, Madrid.

NEWLAND, C. (2000). Exports and terms of trade in Argentina, 1811-1870. Bulletin of Latin American Research, 17(3), 409-416. DOI: 10.1111/j.1470-9856.1998.tb00132.

Newland, C. y Gallo, A. (2004). Globalización y convergencia de precios en el imperio español, 1660-1810. Revista de Historia Económica/ Journal of Iberian and Latin American Economic History, 22(3), 573-596. DOI: 10.1017/S0212610900011666

ÖzMucur, S. y SEVket, P. (2007). Did European commodity prices converge during 1500-1800? The new comparative economic history: Essays in honor of Jeffrey G. Williamson. En T. J. Hatton, J. H. O'Rourke y A. M. Taylor (eds.), The new comparative economic history (pp. 59-85). Cambridge: Massachusetts Institute of Technology Press.

PALOMEQUe, S. (1989). La circulación mercantil en las provincias del interior argentino entre 1800 y 1810. Anuario IEHS: Instituto de Estudios Histórico-Sociales, 4, 131-210.

Parolo, M. P. (2015). Canastas de consumo y costos de subsistencia en Tucumán a mediados del siglo XIX. Revista Población E̊ Sociedad, 22(2), 27-59. Recuperado de http://www.poblacionysociedad.org.ar/archivos/22/P\&S-V22-N2-Parolo.pdf 
Politis, G. G. (1984). Climatic variations during historical times in eastern Buenos Aires Pampas, Argentina. Quaternary of South America and Antarctic Peninsula, 2, 133-161.

Quiroz, E. (2005). Entre el lujo y la subsistencia: mercado, abastecimiento y precios de la carne en la ciudad de México, 1750-1812. México: El Colegio de México.

Robertson, J. P. y Robertson, G. P. (1950). Cartas de Sudamérica. Buenos Aires: Emecé.

Rosal, M. A. (2003). Flujos comerciales e integración económica del espacio rioplatense hacia el final del periodo rosista. En M. S. IRIGoin y R. Schmit (eds.), La desintegración de la economía colonial. Comercio y moneda en el interior del espacio colonial (1800-1860) (pp. 227-250). Buenos Aires: Biblos.

Rosal, M. A. y Schmit, R. (2004). Las exportaciones pecuarias bonaerenses y el espacio mercantil rioplatense (1768-1854). En R. Fradkin y J. C. Garavaglia (eds.), En busca de un tiempo perdido. La economía de Buenos Aires en el país de la abundancia, 1750-1865 (pp. 159-194). Buenos Aires: Prometeo.

Schmit, R. (2011). El Río de la Plata desde la tradición colonial a las transformaciones económicas postrevolucionarias. X Congreso Internacional de la Asociación Española de Historia Económica.

TAndeter, E. y Wachtel, N. (1992). Precios y producción agraria en Charcas en el siglo XVIII. En L. JOHnSON y E. TANDETER (comps.), Economías coloniales: precios y salarios en América Latina, siglo XVIII (pp. 221-301). Buenos Aires: Fondo de Cultura Económica.

TARRAGÓ, G. (1994). Elite, parentesco y comercio en Santa Fe en el siglo XVIII. Anuario de la Escuela de Historia, 16, 175-187.

Tuella, P. (15 de agosto de 1802). Examen crítico sobre las reflexiones político-económicas. Telégrafo Mercantil, t. IV, 16.

\section{OTRAS FUENTES CONSULTADAS}

\section{Archivos}

ACFSF Archivo del Convento de San Francisco, Santa Fe, Argentina.

ACSC Archivo del Convento Franciscano de San Carlos, San Lorenzo, Argentina.

ADEEC Archivo del Departamento de Estudios Etnográficos y Coloniales, Santa Fe, Argentina.

AGN Archivo General de la Nación, Buenos Aires, Argentina.

AgPSF Archivo General de la Provincia de Santa Fe, Santa Fe, Argentina.

AMHPR Archivo Museo Histórico Provincial de Rosario Dr. Julio Marc, Rosario, Argentina.

Registro Oficial de la Provincia de Santa Fe. 